Type: Literature review

Title: Using non-invasive transcranial Direct Current Stimulation for Neglect and Associated Attentional Deficits following Stroke

Running head: The role of tDCS in neglect therapy

Keywords: neglect, tDCS, attention, vigilance, stroke

Authors:

Elena Olgiati ${ }^{1,2}$ \& Paresh A. Malhotra ${ }^{1,2,3}$

${ }^{1}$ Department of Brain Sciences, Imperial College London

${ }^{2}$ Imperial College Healthcare NHS Trust

${ }^{3}$ UK Dementia Research Institute at Imperial College London

EO Twitter: @OlgiatiE

PM ORCID ID 0000-0002-1897-0780, Twitter: @pareshmalhotra

Corresponding author: Elena Olgiati, e.olgiati@imperial.ac.uk

Word count: 7306

\begin{abstract}
Neglect is a disabling neuropsychological syndrome that is frequently observed following right-hemispheric stroke. Affected individuals often present with multiple attentional deficits, ranging from reduced orienting towards contralesional space to a generalised impairment in maintaining attention over time. Although a degree of spontaneous recovery occurs in most patients, in some individuals this condition can be treatment-resistant with non-spatial deficits being particularly persistent. Moreover, there is a large inter-individual variability in response to different therapeutic approaches. Given its potential to alter neuronal excitability and affect neuroplasticity, non-invasive brain stimulation is a promising tool that could potentially be utilised to facilitate recovery. However, there are many outstanding questions regarding its implementation in this heterogeneous patient group.
\end{abstract}

Here we provide a critical overview of the available evidence on the use of non-invasive electrical brain stimulation, with a focus on transcranial direct current stimulation (tDCS), to improve neglect and associated attentional deficits after right-hemispheric stroke. At present, there is not enough robust evidence supporting the clinical use of tDCS to alleviate symptoms of neglect. Future research would benefit from careful study design, enhanced precision of electrical montages, multi-modal approaches that explore predictors of response, tailored dose-control applications and increased efforts to understand the potential of tDCS, as a stand-alone technique and in synergy with other available treatments for neglect. 


\section{The Neglect syndrome}

Attention deficits represent the most common cognitive sequelae following right-hemispheric stroke (Vallar \& Bolognini, 2014). The neglect syndrome is an heterogenous condition, currently considered a multi-component syndrome (Heilman, Valenstein, \& Watson, 2000; Husain, 2008; Husain \& Rorden, 2003; Mesulam, 2000). It is associated with poor motor recovery and higher disability, hindering patients' response to rehabilitation (Buxbaum et al., 2004; Cherney, Halper, Kwasnica, Harvey, \& Zhang, 2001; Katz, Hartman-Maeir, Ring, \& Soroker, 1999; Paolucci, Antonucci, Grasso, \& Pizzamiglio, 2001). Compared to other patient groups with similar lesion volume, patients with neglect consistently score lower at both admission and discharge on established measures of functional ability as well as activities of daily living (Denes, Semenza, Stoppa, \& Lis, 1982; Jehkonen et al., 2001; Kalra, Perez, Gupta, \& Wittink, 1997).

Clinically, patients present with an array of attention deficits but in varying combinations. At the broadest level, all patients with neglect initially manifest spatially lateralised deficits, characterised by a disparity in performance in the left vs. right hand side of the space, which often presents in tandem with non-lateralised cognitive deficits, such as a diminished ability to maintain attention over time. In addition, patients frequently show associated impairments which are not characteristics of neglect per se. These include a lack of awareness into their condition (i.e., anosognosia) and disorders of body representation (e.g., somatoparaphrenia), which can further hinder rehabilitation (Li \& Malhotra, 2015).

Sufferers from both left and right hemisphere stroke often show signs of neglect in the acute post-stroke stages, but this pattern becomes unbalanced quite rapidly, with right-hemispheric stroke patients suffering from left neglect forming the majority of individuals affected in more chronic stages (Stone, Patel, \& Greenwood, 1993; Stone, Patel, Greenwood, \& Halligan, 1992; Stone et al., 1991).

In order to develop effective treatment strategies for neglect, it is critical to have a clear understanding of potential therapeutic targets. To do so, it is essential to appreciate the complex interplay between the component deficits in neglect and how these deficits evolve over time. Below we briefly summarise the cognitive pathophysiology and natural history of visual neglect. In line with the main body of neglect research, this review will focus on neglect as it manifests in the visual modality; it has however been documented to co-occur in other sensory modalities (for a review, see Brozzoli, Demattè, Pavani, Frassinetti, \& Farnè, 2006).

\subsection{Lateralised bias in Neglect}

The cardinal feature of neglect consists of a spatial bias away from the contralesional side. Whilst on hyperacute wards, patients typically present with a marked ipsilesional deviation of head and eyes (Fruhmann Berger, Pross, Ilg, \& Karnath, 2006) and appear to ignore events occurring in contralesional space. This can be demonstrated through observation of spontaneous behaviour as well as numerous standardised tests (see Figure 1 for examples of tests performed by patients with neglect). Cancellation tasks are particularly popular as they provide a quantifiable measure of neglect severity (Figure 2). Although the lateralised aspect of neglect recovers in the majority of patients, and appears to improve faster than other general attention deficits (Karnath, 1988), it represents the key modifiable target in the majority of treatment studies, following on from its striking clinical manifestations and defining role in diagnosis. 
- Insert Figure 1 about here -

\subsection{Non-lateralised deficits in Neglect}

The neglect syndrome is also characterised by attention deficits affecting both sides of the space. Relatives and therapists of right-hemispheric stroke patients commonly describe affected individuals as distracted, as if they were not listening when being spoken to (Robertson, 2001), no matter which side of the space they are being approached from. Examples of well documented non-lateralised components of neglect are selective attention deficits (i.e., the 'attentional blink' (Husain, Shapiro, Martin, \& Kennard, 1997)), impairment of spatial working memory (Malhotra, Mannan, Driver, \& Husain, 2004; Pisella, Berberovic, \& Mattingley, 2004; Striemer, Ferber, \& Danckert, 2013) and of vigilant attention (Husain \& Rorden, 2003; Malhotra, Coulthard, \& Husain, 2009; Robertson, 1993). Chronic patients often manifest such persisting attention deficits that affect both sides of space (Corbetta \& Shulman, 2011; Husain \& Rorden, 2003; Manly, 2002; Robertson, 1993; van Kessel, van Nes, Brouwer, Geurts, \& Fasotti, 2010), and complain about severe and long-lasting impairment in the ability to maintain concentration when reading, following TV programmes, or engaging in other prolonged activities such as therapy sessions. In a recent study by Nurmi and colleagues (Nurmi et al., 2018), the researchers followed patients with mild neglect in their first year after stroke and observed a longitudinal reduction in spatial bias as measured on cancellation tasks, with omissions becoming evenly distributed in space - a pattern which indicates persisting non-lateralised deficits, rather than ongoing pathological lateralised bias. This is also reflected in our clinical experience working with patients affected by severe neglect at presentation, who often demonstrate a non-lateralised pattern of omissions when re-tested in later stages post-stroke (Figure 2). Critically, it seems to be this non-lateralised attentional component of neglect that better predicts the chronicity and functional disability associated with neglect (Duncan et al., 1999; Hjaltason, Tegner, Tham, Levander, \& Ericson, 1996; Husain et al., 1997; Peers, Cusack, \& Duncan, 2006; Robertson, Manly, et al., 1997).

\section{- Insert Figure 2 about here -}

\subsection{Interventions for neglect}

Examples of behavioural interventions that have been attempted to remediate the ability to detect contralesional targets in neglect include visual scanning training (for a review, see Pizzamiglio, Guariglia, Antonucci, \& Zoccolotti, 2006), limb activation training, involving either active (Robertson \& North, 1993; Robertson, North, \& Geggie, 1992) or passive (Ladavas, Berti, Ruozzi, \& Barboni, 1997) movements of the contralesional upper limb, visuomotor feedback training (Harvey, Hood, North, \& Robertson, 2003; Robertson, Nico, \& Hood, 1997; for home-based therapy see Rossit et al., 2019), and virtual reality training (Kim, Chun, Yun, Song, \& Young, 2011; Sedda et al., 2013). Experimental evidence exists for each of these techniques, but there are no convincing randomised trials demonstrating clinically significant improvements as yet - this may well be attributable to patient heterogeneity and the difficulty in observing a therapeutic effect in a recovering population. Given that patients typically struggle to appreciate the extent of their attention deficits, an associated deficit known as anosognosia, bottom-up strategies that do not rely on voluntary reorienting have also been trialled. One of them is prism adaptation, which involves having the patient wearing goggles made of prism wedges during repeated pointing (Rossetti et al., 1998). Despite encouraging results, prism adaptation has not proven efficacious in larger and more robust randomised clinical trials (for instance, see Rode et al., 2015). 
More recently, approaches targeting the non-lateralised components of neglect have been developed (Jacquin-Courtois, 2015). Phasic alerting achieved via the presentation of alerting sounds (Robertson, Mattingley, Rorden, \& Driver, 1998; Robertson, Tegner, Tham, Lo, \& Nimmo-Smith, 1995; Thimm, Fink, Kust, Karbe, \& Sturm, 2006) and drug therapies such as Guanfacine (Dalmaijer et al., 2018; Malhotra, Parton, Greenwood, \& Husain, 2006), aimed at boosting arousal and sustained attention, have showed promising preliminary results at a proof-of-concept level.

\subsubsection{Non-invasive brain stimulation approaches}

One further avenue for improving both the lateralised and non-lateralised deficits in neglect involves the use of non-invasive brain stimulation. There have been a number of studies looking at the effects of transcranial magnetic stimulation, which relies on the induction of a depolarising current through the targeted application of a magnetic field. The majority of these studies have aimed to redirect spatial attention away from ipsilesional space and towards contralesional space, and have shown some efficacy, particularly with the use of so-called theta-burst protocols (Cazzoli et al., 2012; Fu et al., 2015; Koch et al., 2012; Nyffeler, Cazzoli, Hess, \& Muri, 2009; Zebhauser, Vernet, Unterburger, \& Brem, 2019). Here we will focus on transcranial direct current stimulation, a neuromodulatory technique that involves the use of a low-intensity electric current to alter brain network activity, and hence function (Knotkova, Nitsche, Bikson, \& Woods, 2019).

\section{Transcranial Direct Current stimulation}

Transcranial Direct Current Stimulation (tDCS) allows the non-invasive modulation of spontaneous brain network activity (Bikson et al., 2016). By promoting changes in cortical excitability, the application of a low-intensity (typically 0.5-2 mA) (Zaghi, Acar, Hultgren, Boggio, \& Fregni, 2010) constant electrical current can drive brain activity and facilitate/interfere with a cognitive function (see review by Kolb, Teskey, \& Gibb, 2010; and comprehensive technical guide to tDCS by Woods et al., 2016). Given its potential to affect plasticity, tDCS may be a particularly useful tool to enhance cognition in the context of neurorehabilitation (Vallar \& Bolognini, 2011). Certain characteristics, such as being noninvasive, relatively cheap and mostly well-tolerated, with transient and mild side effects, make it particularly appealing for clinical research aiming to augment cognitive functions following a brain insult. With evidence of efficacy in healthy individuals accumulating (Polania, Nitsche, \& Ruff, 2018), the use of tDCS to improve post-stroke outcomes has become a popular area of exploration, particularly in the motor (Stagg \& Johansen-Berg, 2013) and language domains (Fridriksson et al., 2018; Holland \& Crinion, 2012).

Nonetheless, its use is controversial (e.g., see Filmer, Mattingley, \& Dux, 2019; Horvath, Forte, \& Carter, 2015; Opitz, Falchier, Linn, Milham, \& Schroeder, 2017), and there are ongoing debates regarding its clinical effectiveness (Cappon, Jahanshahi, \& Bisiacchi, 2016; Kekic, Boysen, Campbell, \& Schmidt, 2016).

Below we discuss a framework of critical parameters that require careful consideration when designing and evaluating a treatment involving the application of tDCS in stroke patients, before proceeding to discuss the potential uses of tDCS in neglect.

\subsection{Stimulation polarity and directionality}

The canonical assumption in the tDCS literature is that anodal stimulation will cause a physiological increase in cortical excitability, with the intended behavioural effect of upregulating activity in the stimulated area; conversely, cathodal stimulation will decrease 
cortical excitability, inhibiting brain activity (Nitsche \& Paulus, 2000). However, this dualpolarity model has been recently reconsidered, with reported outcomes in the opposite direction. For instance, in the motor domain researchers recently found considerable variability in response to stimulation, with about $36 \%$ of participants showing the standard pattern of anodal stimulation producing facilitation and cathodal stimulation causing inhibition (Wiethoff, Hamada, \& Rothwell, 2014). Results from studies examining effects on regions outside motor cortex appear to be even more complex (Brückner \& Kammer, 2017; Jacobson, Koslowsky, \& Lavidor, 2012; Li, Violante, Leech, et al., 2019).

An alternative approach to focussing on the effects of electrode polarity at a single electrode location is to focus on stimulation directionality: it is clear that current leaves the anode and passes through the cortex while travelling to the cathode, affecting neuronal resting-state potentials. However, it not only influences the area directly beneath or near the electrodes, but has more widespread effects including relatively distant areas (Lang et al., 2005). By using ex-vivo modeling and simulations of current flow, based on realistic head models, it is becoming increasingly possible to develop a better understanding of the most likely effects achievable with different electrodes configuration (Bikson, Rahman, \& Datta, 2012).

\subsection{Online vs Offline tDCS}

Recent studies have highlighted that the timing of stimulation in relation to a function of interest is a key variable in determining the effect of tDCS (Pirulli, Fertonani, \& Miniussi, 2013, 2014; Stagg et al., 2011; Stagg \& Nitsche, 2011). From a methodological perspective, tDCS studies can be distinguished between online and offline paradigms, depending on whether activity is carried out whilst receiving brain stimulation. In this context, online refers to studies whereby tDCS is applied during behavioural task performance, whereas offline indicates protocols where tDCS is applied prior to commencing a task or training. It is possible that if a task is performed whilst receiving stimulation (online), tDCS may act on the networks and brain regions which are most active during brain stimulation - meaning that the choice of the task performed during stimulation is likely to be important in determining its effect. It should be noted that in cases where tDCS is applied at rest, any task performed immediately before stimulation may also have primed brain networks - this information has not been always reported in studies utilising offline paradigms, but it is potentially relevant for interpreting conflicting evidence in the literature. Furthermore, tDCS and training may interact, but not necessarily leading to additive effects (e.g., see Muller-Dahlhaus \& Ziemann, 2015). The online/offline distinction is particularly relevant in the context of neurorehabilitation, as tDCS might potentially be applied as an 'add-on' before or during (physical or cognitive) rehabilitation therapy sessions. More studies looking at the comparability of online and offline stimulation in clinical populations would be extremely helpful to clarify which might be more efficacious.

\subsection{State-dependent tDCS}

In an effort to increase understanding of the factors behind the large interindividual variability in tDCS outcomes (Wiethoff et al., 2014), studies in healthy volunteers have explored how the state of the brain at tDCS delivery may influence response to tDCS (Li, Uehara, \& Hanakawa, 2015). In addition to behaviour prior/during stimulation as discussed in the section above, potential state-related factors include baseline network activity (Antal, Terney, Poreisz, \& Paulus, 2007; Li, Violante, Leech, et al., 2019), education status (Berryhill \& Jones, 2012) and baseline task sensitivity (Benwell, Learmonth, Miniussi, Harvey, \& Thut, 2015; Learmonth, Thut, Benwell, \& Harvey, 2015; Tseng et al., 2012). This 
line of investigation in healthy individuals highlights the importance of considering the behavioural/network baseline on which to map the effect of tDCS.

\subsection{Timing of stimulation}

Another point for consideration for when designing a clinical study regards the optimal timing of treatment in relation to stroke onset. There is very little evidence to suggest an optimal therapeutic window to administer tDCS. Most studies in the literature have applied tDCS in the post-acute and chronic stages post-stroke, allowing a degree of spontaneous recovery to occur before applying tDCS. Interestingly, those studies that explored the potential of an early application of tDCS (either alone or administered during rehabilitation), showed that the degree of (motor) improvement was greater at follow-up rather than at treatment cessation (Andrade et al., 2017; Bornheim, Croisier, Maquet, \& Kaux, 2019; Sattler et al., 2015). However, a number of researchers (Di Lazzaro et al., 2014; Rossi, Sallustio, Di Legge, Stanzione, \& Koch, 2013) have not found evidence supporting a role for stimulation in the acute setting.

\section{5 tDCS sessions}

There is no standard definition of tDCS dose in clinical studies. The dose-response relationship for tDCS appears to be complex and non-linear in healthy individuals (Jamil et al., 2017), and has not been systematically investigated in clinical populations.

Typical dosage in clinical studies involves 10-20 minutes of 0.5-2mA tDCS delivered via two large electrodes. Studies may vary as to how many sessions of tDCS are administered. In a common tDCS design, a single bout of stimulation is applied and any change in behavioural measures is recorded and compared to a sham group/session. If two or more stimulation conditions are compared, a washout period between session of variable duration is specified in the protocol (Monte-Silva, Kuo, Liebetanz, Paulus, \& Nitsche, 2010).

Physiologically, a single tDCS session is considered to induce short-term acute effects on cortical excitability, with after-effects lasting for about an hour (Nitsche et al., 2003). In multiple-session approaches, the effect of the repeated application of tDCS, applied once a day for several days, are evaluated. There is evidence showing accumulation of modulatory effects following the repeated application of tDCS over consecutive sessions (Alonzo, Brassil, Taylor, Martin, \& Loo, 2012; Reis et al., 2009; Waters-Metenier, Husain, Wiestler, \& Diedrichsen, 2014), with long-lasting LTP-like effects persisting beyond 24 hours in healthy humans (Monte-Silva et al., 2013).

\section{6 tDCS blinding}

One of the main advantages of tDCS as compared to other forms of neurostimulation is its natural placebo condition, assumed to be undistinguishable from the active condition: the current is ramped-up, plateaued and then ramped-down in a few seconds producing sensations on the skin comparable to active stimulation, but without neuromodulatory effects (Nitsche et al., 2008). There are reports suggesting that blinding can be difficult to achieve with intensities of 2mA (O'Connell et al., 2012) and even 1mA (Greinacher, Buhôt, Möller, \& Learmonth, 2019; Turi et al., 2019) in younger healthy participants. Blinding effectiveness in older and clinical populations has been less investigated; available evidence however suggests that blinding of participants and investigators is as successful in these populations, at least when tDCS is applied over the motor cortices (e.g., see Gandiga, Hummel, \& Cohen, 2006). Some recent evidence suggests that the majority of healthy older adults do not appear to feel the cutaneous sensation as much as younger participants (Gandiga et al., 2006; 
Kessler, Turkeltaub, Benson, \& Hamilton, 2012; Wallace, Cooper, Paulmann, Fitzgerald, \& Russo, 2016). Our personal experience with stroke patients also suggests that this clinical population reported less discomfort than healthy younger individuals.

\subsection{Stimulation focality}

In conventional tDCS, current is typically applied to the scalp via two large (typically $5 \times 7 \mathrm{~cm}$ or $5 \times 5 \mathrm{~cm}$ ) saline-soaked sponge electrodes kept in position using non-conductive elastic straps. They may be positioned above the same hemisphere (as in single-mode tDCS) or above regions in both hemispheres (as in dual-mode or oppositional tDCS, when the reference electrode is sited at the contralateral homologue area). Alternatively, in extracephalic montages, the cathode is placed over the deltoid muscle or the neck. The spatial resolution of stimulation achievable with such montages is low, with current spreading over several gyri (Nitsche et al., 2007) (Figure 3). Thus, conventional tDCS with bipolar large electrodes is thought to activate not only the region of interest but also collateral cortical and subcortical tissue (Moreno-Duarte et al., 2014). Computational studies have confirmed wide electrical field distributions, with maximum field strengths not located directly underneath the electrodes but at an intermediate location, outside of the desired target region (Datta et al., 2009; Klaus \& Schutter, 2018).

There is growing interest in transcending the use of two large electrode pads in favour of High Definition (HD) tDCS montages featuring smaller electrodes to increase precision and focality to a desired target (Datta et al., 2009; Dmochowski, Datta, Bikson, Su, \& Parra, 2011; Dmochowski et al., 2013; Dmochowski, Koessler, Norcia, Bikson, \& Parra, 2017; Guler et al., 2016; Ruffini, Fox, Ripolles, Miranda, \& Pascual-Leone, 2014; Sadleir, Vannorsdall, Schretlen, \& Gordon, 2012; Saturnino, Madsen, Siebner, \& Thielscher, 2017; Wagner et al., 2016). Local targeting has been achieved using varied electrode configurations, typically one source electrode surrounded by two or more sinks, including concentric-ring configurations (Kuo et al., 2013). In HD-tDCS setups, electrodes are arranged in close proximity, leading to a substantial shunting of the current through the scalp without reaching deeper brain regions, as achievable with distant large pads (Huang \& Parra, 2018). Denser electrode arrays of HD-tDCS therefore seem ideal when trying to confine the area of stimulation and constrain the current in the spatially constrained superficial area between the electrodes. This renders HD-tDCS particularly appealing in cases of large focal lesions, where the aim is to achieve maximum focality and targeting of spared regions by avoiding current dissipation through the cerebrospinal fluid (CSF) occupying the space once occupied by the lesion.

- Insert Figure 3 about here -

\section{8 tDCS in cases of extensive brain damage}

Some studies have suggested that patients with larger lesion volume (Bolognini et al., 2014), white matter tract disconnection (Bradnam, Stinear, \& Byblow, 2013; Li, Violante, Zimmerman, et al., 2019; Lindenberg, Nachtigall, Meinzer, Sieg, \& Flöel, 2013; Rosso et al., 2014) or more severe deficits (Bradnam, Stinear, Barber, \& Byblow, 2012; Marquez, van Vliet, McElduff, Lagopoulos, \& Parsons, 2015; O'Shea et al., 2014), may demonstrate less benefit from application of tDCS. In these instances, electrode location would appear to be critical, particularly in cases of extensive brain damage following stroke: the current would always follow the path of least resistance (Fernandez-Corazza, Turovets, Luu, Anderson, \& Tucker, 2016), dissipating through the CSF that occupies the lesion space. Targeting 
surviving brain tissue and aiming to ensure that current travels outside the lesioned area would seem a more worthwhile approach. In an effort to avoid stimulating lesioned tissue, electrodes could be positioned above spared regions of the ipsilesional hemisphere or the homologue area in the contralesional hemisphere. At present, it seems that targeting the affected hemisphere may be more effective (Stagg et al., 2012), with a reported detrimental effect of tDCS inhibiting activity of the contralesional hemisphere in severely affected patients (Johansen-Berg et al., 2002).

\section{9 tDCS safety in stroke}

Current safety recommendations for non-invasive brain stimulation include avoiding the use of extra-cephalic montages (i.e., reference placed over the deltoid muscle or the neck) in frail populations such as the elderly and individuals with comorbidities, because of its increased risk of shunting of electric current through the skin and the risk of influencing brainstem activity (List et al., 2015; Vernieri et al., 2010). There should also be rigorous application of exclusion criteria, such as the presence of metallic implants or cardiac pacemakers, a history of epilepsy and the likelihood to change psychoactive medications regimen. For a recent review of safety recommendation when applying tDCS in stroke, see Russo and co-workers (Russo, Carneiro, Bolognini, \& Fregni, 2017).

Although there are no specific guidelines for clinical tDCS studies, all the issues described above have to be carefully considered when deciding on the most appropriate tDCS montage for stroke patients. These factors may contribute to the apparent large inter-individual variability that has been reported in many tDCS studies (e.g., see Wiethoff et al., 2014), which currently poses a critical limit to its clinical translation.

\section{3 tDCS to improve lateralised bias in neglect}

All previous reviews addressing the topic of neuromodulation (including but not exclusively tDCS) for neglect therapy have understandably focused on tDCS-induced modulations of what is considered to be the core deficit of neglect, the lateralised attentional component that causes difficulties in orienting towards the contralesional hemispace (Hesse, Sparing, \& Fink, 2011; Jacquin-Courtois, 2015; Müri et al., 2013; Mylius et al., 2012). We are aware of eleven published studies and one abstract discussing whether tDCS has the potential to improve the spatial bias in neglect (Table 1).

- Insert Table 1 about here -

\subsection{Rationale}

The rationale of tDCS for lateralised deficits in neglect is related to the concept of interhemispheric rivalry, based on the classic model by Kinsbourne (Kinsbourne, 1987; Kinsbourne, 1993). This posits a situation whereby both parietal cortices exert reciprocal inter-hemispherical inhibition, with damage to the right resulting in pathological disinhibition of the left intact cortex. In this context, three alternative tDCS approaches, aimed at modulating pathological interhemispheric interactions favouring a return to a pre-lesional pattern of activity, seem valid: (i) the use of tDCS to increase excitability of the affected hemisphere, (ii) decreasing excitability of the intact hemisphere, or (iii) a combination of these. These three approaches have been utilised by different investigators, with important methodological differences in tDCS protocols between studies. 


\subsection{Stimulation parameters}

Each of the studies listed in Table 1 used the international 10-20 EEG system to locate and position the electrodes over the right damaged (P4) or left intact (P3) posterior parietal cortex, with the exception of two studies targeting the primary motor cortex , (Bornheim, Maquet, Croisier, Crielaard, \& Kaux, 2018; O'Shea et al., 2017). In the case of the study by O'Shea and co-workers, this montage was deliberately chosen with the aim of consolidating sensorimotor after-effects induced by prism exposure.

Stimulation protocols have compared sham stimulation to anodal electrode positioned over the right (Bang \& Bong, 2015; Bornheim et al., 2018; Ko, Han, Park, Seo, \& Kim, 2008) or the left hemisphere (O'Shea et al., 2017), with the reference electrode positioned over the vertex $(\mathrm{Cz})$ or the supraorbital area. In an effort to clarify the best stimulation site and stimulation polarity, some studies included a direct comparison of different montages. For instance, two studies reported an advantage of anodal electrode over the right parietal cortex, as compared to sham stimulation and cathodal electrode over the left parietal cortex, when tDCS was applied in combination with prism adaptation (Chieffo, Arcari, Comi, Comola, \& Leocani, 2019; Ladavas et al., 2015).

Other researchers have reported comparable beneficial effects of anodal/cathodal stimulation over sham, when applied alone (Sparing et al., 2009) or in combination with occupational therapy (Yi et al., 2016). In another study including an oppositional tDCS arm, where concurrent bilateral stimulation of the left and right parietal cortices was achieved by positioning anode and cathode over both parietal cortices, its effects were superior to singlemode tDCS (Sunwoo et al., 2013). This montage was subsequently adopted by three groups (Brem, Unterburger, Speight, \& Jancke, 2014; Smit et al., 2015; Turgut, Miranda, Kastrup, Eling, \& Hildebrandt, 2016): two reported a superiority of real stimulation, when compared to sham tDCS (Brem, Unterburger, Speight, \& Jancke, 2014; Turgut et al., 2016), whereas one reported no effect of tDCS over sham (Smit et al., 2015).

All the studies listed in Table 1 delivered tDCS using two big sponge square or rectangular electrodes (area $25 \mathrm{~cm}^{2}$ or $35 \mathrm{~cm}^{2}$ for each electrode), but otherwise differed from each other in a number of stimulation parameters. Current was applied at $2 \mathrm{~mA}$ in six studies (Bornheim et al., 2018; Ko et al., 2008; Ladavas et al., 2015; Smit et al., 2015; Turgut et al., 2016; Yi et al., 2016) - in the study carried out by Turgut and co-workers the current was lowered down to $1.5 \mathrm{~mA}$ in cases of poor tolerability - with remaining studies using lower intensities (Bang \& Bong, 2015; Brem, Unterburger, Speight, \& Jancke, 2014; Chieffo et al., 2019; O'Shea et al., 2017; Sparing et al., 2009; Sunwoo et al., 2013). tDCS was applied for different amounts of time: from 10 (Sparing et al., 2009) and 20 minutes protocols (Bang \& Bong, 2015; Bornheim et al., 2018; Brem, Unterburger, Speight, \& Jancke, 2014; Ko et al., 2008; Ladavas et al., 2015; O'Shea et al., 2017; Smit et al., 2015; Sunwoo et al., 2013; Turgut et al., 2016), up to 30 minutes protocols (Yi et al., 2016).

\subsection{Participant groups}

All patients enrolled in these studies had been diagnosed with neglect. The number of participants varied considerably, from single-case studies (Bornheim et al., 2018; Brem, Unterburger, Speight, \& Jäncke, 2014) to group studies including 32 individuals. Smit and colleagues observed that a major concern for tDCS studies in this clinical population is feasibility (Smit et al., 2015). They identified a population of 89 potential candidates, but only managed to recruit 5 individuals, mainly because a large proportion of patients had exclusion criteria for tDCS (e.g., epilepsy, the presence of metal implants). Ladavas and co- 
workers reported that they could only recruit a third of their initial sample for similar reasons (Ladavas et al., 2015). However, the other studies listed in Table 1 did not include information regarding the number of excluded individuals (Bang \& Bong, 2015; Bornheim et al., 2018; Brem, Unterburger, Speight, \& Jancke, 2014; Chieffo et al., 2019; Ko et al., 2008; O'Shea et al., 2017; Sparing et al., 2009; Sunwoo et al., 2013; Turgut et al., 2016; Yi et al., 2016). For a recent clinical trial on this issue of feasibility of tDCS for neglect rehabilitation, see Learmonth and colleagues (Learmonth et al., 2020).

The time between stroke onset and study participation varied considerably between studies: patients in the acute/subacute stage (within 3 months post-stroke) were included in seven studies (Bang \& Bong, 2015; Bornheim et al., 2018; Brem, Unterburger, Speight, \& Jäncke, 2014; Chieffo et al., 2019; Ko et al., 2008; Turgut et al., 2016; Yi et al., 2016), patients with chronic neglect (over 3 months post-stroke) were included in three studies (O'Shea et al., 2017; Smit et al., 2015; Sunwoo et al., 2013). The remaining two studies included a mix of patients in subacute and chronic stages (Ladavas et al., 2015; Sparing et al., 2009).

\subsection{Study Design}

In terms of experimental design, all studies were sham-controlled and utilised either a crossover design (Chieffo et al., 2019; Ko et al., 2008; Smit et al., 2015; Sparing et al., 2009; Sunwoo et al., 2013) or a between-participants design (Bang \& Bong, 2015; Ladavas et al., 2015; Turgut et al., 2016; Yi et al., 2016), with the exception of one $n=1$ design (Brem, Unterburger, Speight, \& Jancke, 2014) and two series of case studies (Bornheim et al., 2018; O'Shea et al., 2017). A control group of young individuals was included in two studies (O'Shea et al., 2017; Sparing et al., 2009).

Intervention duration varied between a single session and 20 sessions. Proof-of-principle studies examined the effect of one application of tDCS (Chieffo et al., 2019; Ko et al., 2008; Sparing et al., 2009; Sunwoo et al., 2013) on different measures of spatial bias, with a washout period between sessions of at least three hours (Sparing et al., 2009), one day (Chieffo et al., 2019; Sunwoo et al., 2013), two days (Ko et al., 2008) or one month (O'Shea et al., 2017). In the case of the study by Chieffo and co-workers, tDCS was coupled with prism exposure (Chieffo et al., 2019).

Although the repetitive application of tDCS over consecutive sessions during wakeful rest was trialled by two studies (Bornheim et al., 2018; Smit et al., 2015), most studies implemented tDCS as an add-on therapy, delivered over consecutive sessions in combination with other interventions such as prism adaptation (Ladavas et al., 2015; O'Shea et al., 2017), feedback training (Bang \& Bong, 2015), optokinetic stimulation (Turgut et al., 2016) with eye movement protocols (Brem, Unterburger, Speight, \& Jancke, 2014), and standard occupational therapy (Yi et al., 2016).

\subsection{Outcome}

The majority (eleven out of twelve) of the studies showed a significant improvement on different measures of spatial bias after tDCS application, whereas one study reported a null result (Smit et al., 2015). However, the effects of stimulation were often different across common outcome variables, suggesting possible dissociations. Visual perception was assessed using different tasks, such as cancellation tasks, line bisection and drawing tests. These tap into related but different mechanisms, and patients' performance can vary in a given patient depending on the test used (Azouvi et al., 2006). Most studies reported 
significant tDCS-related improvements on the line bisection task - this is the task that shows most response to the placement of the anodal electrode over the right posterior parietal cortex (Bang \& Bong, 2015; Brem, Unterburger, Speight, \& Jancke, 2014; Ko et al., 2008; Sparing et al., 2009; Sunwoo et al., 2013; Yi et al., 2016). Classic measures of visual search were found to respond to tDCS in a minority of studies: two of them examined performance on cancellation tasks (Ko et al., 2008; Yi et al., 2016), one used a motor-free visual perception task (Bang \& Bong, 2015) and one study examined the after-effects of tDCS coupled with prisms with 'invisible' pointing straight ahead (Chieffo et al., 2019). Finally, an improvement in drawing (object copying) was found in the recent study by Turgut and colleagues (Turgut et al., 2016).

The series of case studies by Bornheim and colleagues presented anecdotal evidence for a beneficial effect on different measures of the spatial bias, but no statistics was applied to support the claim (Bornheim et al., 2018).

Other studies utilised computerised batteries of experimental tasks. In the single-case study by Brem (Brem, Unterburger, Speight, \& Jancke, 2014), tDCS induced a significant improvement in performance, as compared to sham stimulation, in a 'Posner' cueing paradigm (Posner, 1980) from the Test of Attentional Performance (TAP) battery (Zimmermann \& Fimm, 2002). Interestingly, a beneficial effect of tDCS was also reported on a non-lateralised simple reaction time from the TAP.

The two studies looking at the synergic application of tDCS with prism adaptation (Ladavas et al., 2015; O'Shea et al., 2017) employed a combined measure to quantify efficacy. Ladavas and co-workers showed bidirectional modulation of tDCS on the Behavioural Inattention Test (BIT) (Wilson, Cockburn, \& Halligan, 1987) total score, depending on stimulation polarity, with anodal facilitating, and cathodal interfering with, prism exposure (Ladavas et al., 2015). Although the BIT is comprised of different conventional and behavioural (e.g., dialling a number, map navigation) tests, statistics for the different subtests were not reported. Similarly, in a series of three longitudinal case-studies, O'Shea and co-workers used a comprehensive neglect battery including line bisection, cancellation and copying tests in addition to a more ecological activity (e.g., filling out a form) for two individuals ( $\mathrm{O}$ 'Shea et al., 2017). Analysis was performed on total percentage of correct responses, with no subscore characterisation.

Other studies suggested a beneficial effect of modulation on spontaneous body orientation (Turgut et al., 2016) and functional measures such as the Barthel Index (Bang \& Bong, 2015) or an activities of daily living (ADL) questionnaire (Brem, Unterburger, Speight, \& Jancke, 2014). In the latter single-case study, ADL had improved at the 3-month follow-up, but was not different at the end of each sham/real treatment week, making it difficult to interpret this result as tDCS related.

To our knowledge, the potential of such interventions involving brain stimulation on neglectrelated phenomena such as anosognosia and somatoparaphrenia has not been investigated, even if these are likely to impact on the outcome of rehabilitation. Barriers to such studies include the relatively low incidence of these phenomena and the lack of accepted primary outcome measures to quantify them.

Those studies that included one stimulation session all examined the immediate behavioural effects of tDCS, with the exception of the study by O'Shea and co-workers (O'Shea et al., 2017). They followed up performance across many timepoints throughout the 
experimental phase (pre and post-stimulation), showing a persisting effect of one application of tDCS + prisms over the follow-up period (18-46 days). In studies employing repeated applications of tDCS, long-lasting effects of tDCS were probed by following patients up for a varying period of time, ranging from 5/6 days (Turgut et al., 2016) to three months (Brem, Unterburger, Speight, \& Jancke, 2014).

\section{4 tDCS to improve non-lateralised attention}

One further approach towards tDCS in patients with neglect is to target non-lateralised largescale brain networks involved in control of attention (Corbetta \& Shulman, 2011). This could help to modulate the more persistent cognitive deficits associated with neglect. To date, there have been very few studies directly examining whether spatial working memory and vigilant attention deficits caused by a focal brain injury are affected by tDCS.

An improvement in measures of spatial working memory following the delivery of tDCS, with anodal-electrode over the right dorsolateral prefrontal cortex (DLPFC), has been described in healthy individuals (Ruf, Fallgatter, \& Plewnia, 2017) and in people with schizophrenia (Schwippel et al., 2018). Furthermore, there is evidence that verbal working memory can be improved in patients with right hemisphere stroke by 30 minutes of tDCS application to left DLPFC (Jo et al., 2009).

More recently, studies have suggested that vigilant attention can be boosted by applying tDCS to the prefrontal cortices in healthy younger (Nelson, McKinley, Golob, Warm, \& Parasuraman, 2014) and older individuals (Brosnan et al., 2018) as well as individuals who have suffered traumatic brain injury (Kang, Kim, \& Paik, 2012), opening up the possibility that this could be implemented for stroke patients too. Kang and co-workers (Kang, Baek, Kim, \& Paik, 2009) reported a positive effect of tDCS on a go/no-go task following a 20 minutes tDCS application with anodal electrode over the left DLPFC in a sample of 10 stroke patients. Interestingly, in this offline paradigm, active tDCS was found superior to sham in boosting accuracy (but not RTs) at 1-hour and 3-hour post-stimulation timepoints, with no detectable changes immediately after stimulation. However, this go/no-go task had minimal requirements in terms of vigilant attention (the task was very brief itself, comprising just 30 trials) and working memory (respond to number ' 1 ' but not number ' 2 ').

In another proof-of-principle study, Park and colleagues chose an unconventional tDCS set up, with two stimulators connected to two anodal electrodes positioned over scalp coordinates F3 and F4 and two cathodal electrodes placed on the nondominant left arm, one next to the other (Park, Koh, Choi, \& Ko, 2013). The intended outcome of this stimulation montage was the simultaneous targeting of bilateral DLPFC. They applied 30 minutes of real/sham tDCS daily, for 5 days/week until discharge, during a computer-assisted rehabilitation program targeting attention and memory. In a between-subjects design that included 11 patients, they reported an improvement in performance post vs pre-treatment on a continuous performance test (CPT) in the tDCS group only. The choice of a betweengroups design, with sub-acute patients affected by either right- $(n=7)$ or left-hemispheric $(n=4)$ lesions, is particularly critical. The two groups (real and sham tDCS) started from a significantly different auditory vigilant attention baseline, which may have influenced the result of the study.

Both these studies explored, for the first time, the potential of tDCS, both alone and in combination with cognitive rehabilitation, to influence general attentional levels in patients 
with stroke. However, the inclusion/exclusion criteria were broad, and patients with lesions throughout the brain were recruited, even though attention problems are typically persisting and disproportionately severe following right-hemispheric stroke (Bowen, McKenna, \& Tallis, 1999; Denes et al., 1982; Ogden, 1985). Both sets of investigators used tasks with non-lateralised stimuli presented in the middle of the screen but did not test for the presence and severity of lateralised attention deficits, which might have been helped in characterising the clinical population. In an effort to develop this line of investigation, we are currently assessing the effects of tDCS in a group of right-hemispheric stroke patients affected by neglect by using a precise targeting of the right-lateralised frontoparietal vigilant attention network (see approach and preliminary results by Olgiati et al., 2019). Damage to this network has repeatedly been demonstrated to be critical in the development of non-lateralised attentional deficits in right hemisphere stroke, and in the pathogenesis of neglect. In addition to the results of our research work, further work will undoubtedly be required to fully evaluate whether there is a therapeutic role for tDCS in the modulation of non-lateralised attentional deficits following stroke. These are common, persistent and associated with poststroke disability, and represent a potential rehabilitation target that has been underexplored (Robertson, 2001; Striemer et al., 2013).

\section{Discussion}

tDCS is a neuromodulatory technique that can promote brain plasticity and foster rewiring after a stroke. However, at present there is no high-quality evidence that tDCS is an efficacious therapy in neglect. This is partly due to methodological issues (e.g., parameter selection), but also to the considerable heterogeneity in this clinical group. In Box 1, we suggest a set of principles that we regard as critical for the future of tDCS research to alleviate the symptoms of neglect; each principle will be discussed below.

- Insert Box 1 about here -

\subsection{Robust study design}

Given the issues described above, it is paramount that scientifically rigorous and robust powered studies are designed (Minarik et al., 2016). This comprises conducting shamcontrolled randomised clinical trials and potentially pre-registering hypothesis, design and analysis to encourage outcome reporting, irrespective of the result. Null findings are critical to gauge treatment efficacy but publication bias against such studies is likely to reduce their visibility in the literature.

A more systematic approach would also require researchers to agree on what points in patient trajectory treatment could be tried. To date, preliminary beneficial effects have been demonstrated at the acute, subacute and chronic stages, and it may well be that combination therapies (e.g. combined tDCS with prism adaptation) are more efficacious before the chronic stage.

The definition of what primary outcome measures to use is also critical. Existing studies have used an array of cognitive tests to examine the efficacy of tDCS, hampering direct comparisons between studies. The effect of tDCS has been frequently assessed using neuropsychological tests that may not be sensitive enough to pick up recovering neglect, or the subtle changes that tDCS is likely to induce (Woods et al., 2016). Also, the clinical relevance of different approaches has been rarely addressed, with only a minority of studies 
exploring whether the crucial issue of whether effects outlasted the session and generalised to function and everyday activities.

\subsection{Identification of response predictors}

Clinical translation and interpretations of conflicting evidence is also limited by a lack of understanding of the neural substrates underlying the effect of tDCS. The use of concurrent techniques, such as EEG or neuroimaging, may help shed light on the poorly understood mechanisms of action of tDCS in healthy and clinical populations (Wiethoff et al., 2014). Understanding how tDCS works is crucial for successful clinical translation, as this could guide paradigm design. In addition, studies aiming to identify predictors of tDCS responsiveness are likely to be particularly helpful in this population. A number of studies have shown differential response to other therapies in neglect, perhaps based on anatomical substrate (Li et al., 2018; Luauté et al., 2006), with tDCS responsiveness that has been recently found linked to anatomical damage in other patient populations (Li, Violante, Zimmerman, et al., 2019). Better identification of those individuals likely to respond to stimulation would enable clear stratification in future trials.

\subsection{Precise targeting of cortical structures}

All the studies described above used conventional tDCS montages that caused the current to travel large distances within the brain, an event which has been found associated with decreased stimulation efficiency (Moliadze, Antal, \& Paulus, 2010). Electromagnetic field simulation techniques are now widely available and can be used to predict brain current flow from surface electrode position (Bikson et al., 2012; Noetscher, Yanamadala, Makarov, \& Pascual-Leone, 2014). They can provide detailed information on focality and depth of penetration, helping to achieve precise targeting or avoidance of specific brain regions. At present, computational modeling is performed using healthy brain tissue. Although a study conducted in three simulated focal lesion profiles found global current density to be comparable to that of the healthy brain (Wagner et al., 2007), additional studies are needed to reliably simulate the effect of tDCS on a lesioned brain, or to gauge the possible the effects of surgery (cranioplasty is increasingly common in this clinical population).

\subsection{Personalised stimulation protocols}

Considering the variability in tDCS responsiveness and the heterogeneity of neglect patients as a group, a one size fits-all approach to stimulation parameters is unlikely to be optimal. Tailoring personalised stimulation prescriptions to the individual, with optimal dosing for instance using real-time adaptation to imaging data or behaviour (Dmochowski et al., 2013; Lorenz et al., 2019), is an attractive solution.

\subsection{Pairing tDCS with other interventions}

tDCS could represent a stand-alone therapy, a substitutive treatment for pharmacotherapy in patients with poor drug tolerability, adverse pharmacological interactions, and where there are limited options. It could also establish itself as an augmentative therapy: its portability and easy setup (potentially wireless, with bluetooth technology integrated in some devices) makes it attractive as an adjunctive therapy that is wearable during rehabilitation. The effectiveness of cognitive rehabilitation might well be enhanced thorugh simultaneous application of brain stimulation, possibly through improved learning ability (Reis et al., 2008). The available evidence is encouraging, but more studies are needed to confirm its incremental effect and whether this is clinically relevant. In a recent meta-analysis of 10 
studies, researchers found moderate-quality evidence of the effectiveness of non-invasive brain stimulation techniques (including but not exclusively tDCS) combined with behavioural interventions (Salazar et al., 2018). Drug-augmented stimulation could also be explored in future studies looking at the combination of pharmacological and electrical stimulation, ideally using a factorial design to test the two interventions simultanously (i.e., sham tDCS, active tDCS, pharmacotherapy, combined therapy).

\section{Conclusion}

The studies described above highlight the key challenge of finding suitable combinations of different therapeutic axes in cognitive rehabilitation, in an effort to augment strength and duration of the effects induced by each of them individually (Harvey \& Kerkhoff, 2015). At present there are insufficient data to support the use of tDCS in patients who have neglect, but the promising results that have been described to date reinforce the need to systematically evaluate this form of brain stimulation in this patient group (Box 1). 


\section{CAPTIONS}

Figure 1: Examples of lateralised bias in neglect, with asymmetries between left and right hemispace

Patients display various degrees of spatial bias when asked to copy a daisy (Wilson, Cockburn, \& Halligan, 1987), draw a clock face from memory (as in the Clock Drawing Test), or when spontaneously produced a portrait of the examiner.

Figure 2: Performance of a patient with neglect on the star cancellation tasks in acute (left) and chronic stage (right) of stroke

In the acute phase, numerous lateralised omissions are suggestive of a severe lateralised deficit; with time, performance changes into a more balanced pattern, with non-lateralised omissions (circled in red) indicating a generalised difficulty with vigilance.

Figure 3: Electric fields associated with anodal electrode over $\mathrm{P} 4$ and return over $\mathrm{CZ}$. Values are shown as electrical field magnitude $(\|\mathrm{E}\|=\mathrm{V} / \mathrm{m})$. This visualisation was created with StimViewer, a software package embedded in the Neuroelectrics Instrument Controller. It should be noted that this visualisation is based on simulation of healthy brain tissue.

Table 1: Lesion studies using tDCS to improve lateralised bias in neglect. Participants: Right-Brain Damage (RBD), Left-Brain Damage (LBD); Desired target area: Posterior Parietal Cortex (PPC), Parietal (P), Primary Motor cortex (M1); Outcome measures: Test of Attentional Performance (TAP), NEglect-Test (NET), Activities of Daily Living (ADL), Behavioural Inattention Test (BIT), Gamma aminobutyric acid (GABA), Barthel Index (BI), Catherine Bergego Scale (CBS), Clock Drawing Test (CDT), Functional Independence Measure (FIM).

Box 1: Next steps for neglect therapy using tDCS 
Figure 1

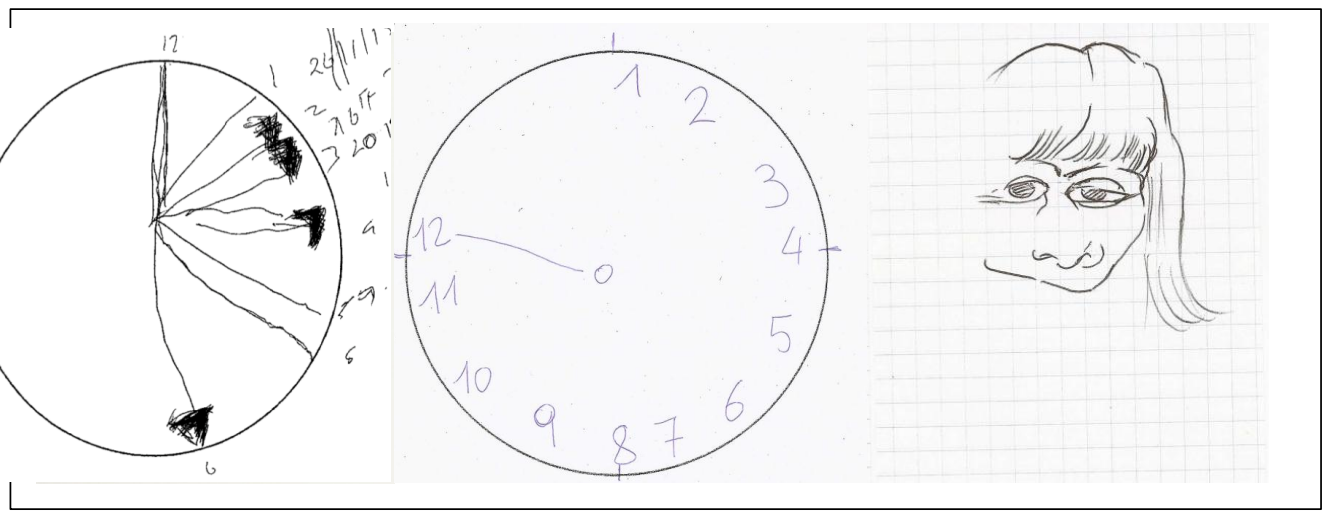



Figure 2
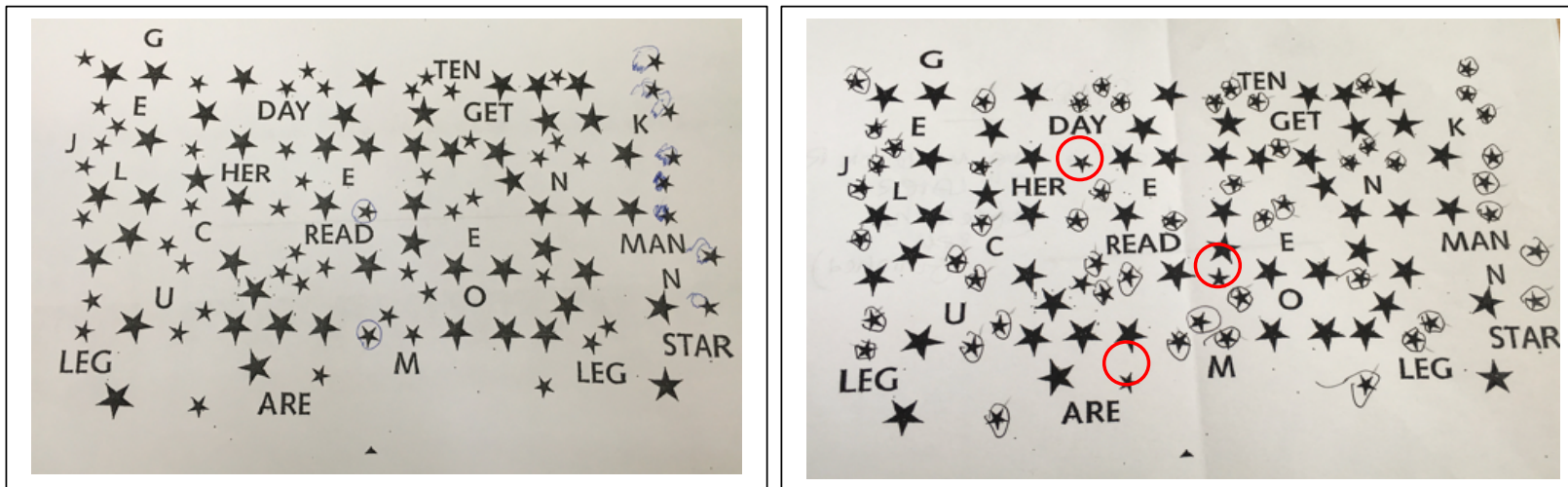
Figure 3

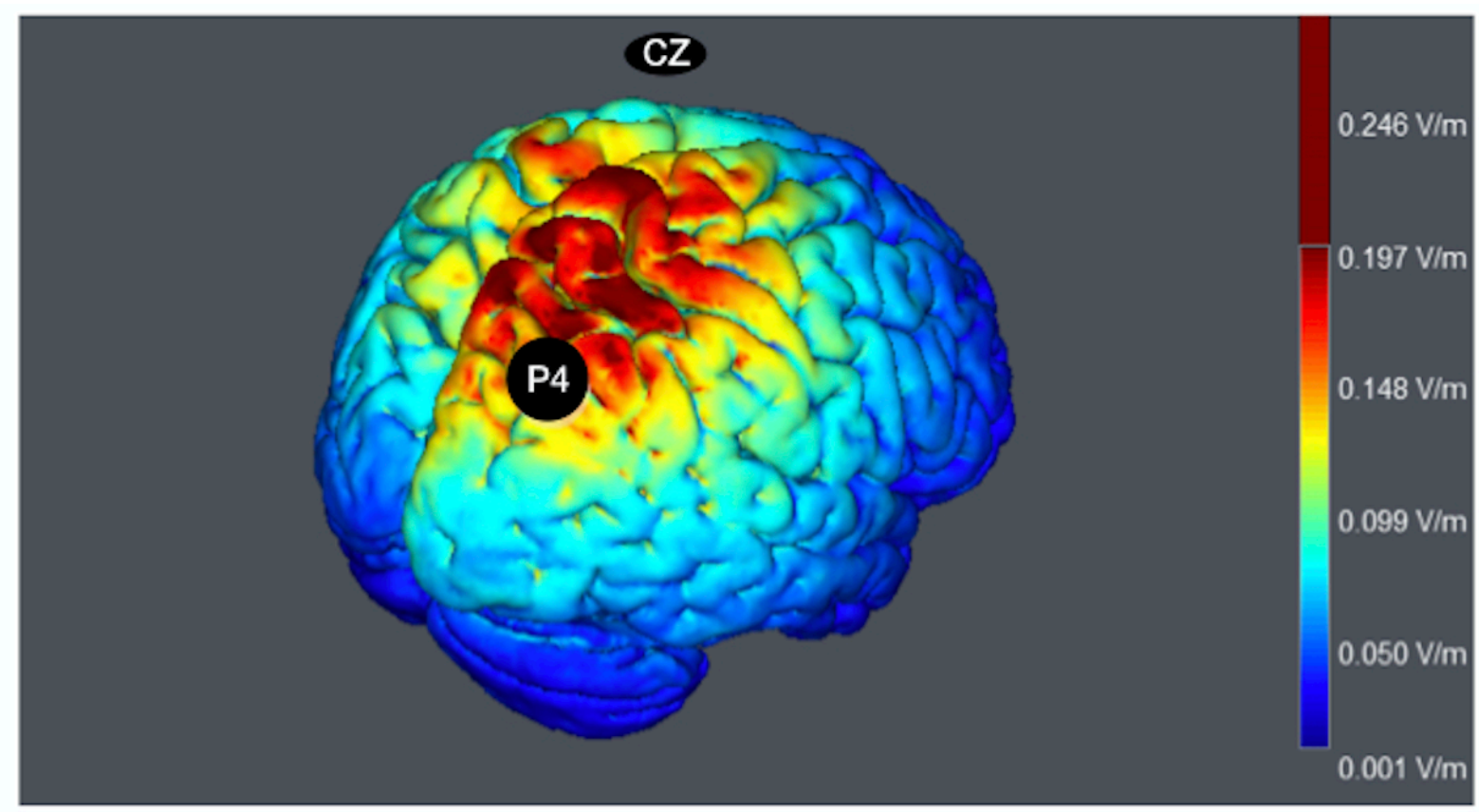


Box 1

The 5 Principles (Ps) of improving tDCS studies in stroke and neglect

POWERED and robust study design

PREDICTORS of tDCS responsiveness

PRECISE targeting of cortical structures

PERSONALISED stimulation prescriptions

PAIRING tDCS with other interventions 
Table 1

\begin{tabular}{|c|c|c|c|c|c|c|c|c|c|c|}
\hline Study & Participants & $\begin{array}{l}\text { Study } \\
\text { design }\end{array}$ & $\begin{array}{l}\text { Time post- } \\
\text { stroke }\end{array}$ & Intensity & Duration & Sessions & Online/Offline & Coupling & $\begin{array}{c}\text { Desired } \\
\text { target }\end{array}$ & Outcome measures \\
\hline $\begin{array}{l}\text { Ko et al., } \\
2008\end{array}$ & $\begin{array}{l}15 \text { RBD } \\
\text { with } \\
\text { neglect }\end{array}$ & $\begin{array}{l}\text { Double- } \\
\text { blind, sham- } \\
\text { controlled, } \\
\text { crossover }\end{array}$ & $1-3$ months & $2 \mathrm{~mA}$ & $20 \mathrm{~min}$ & 1 real 1 sham & Offline & Rest & Right PPC & $\begin{array}{l}\text { Line bisection, symbol } \\
\text { cancellation, letter } \\
\text { cancellation }\end{array}$ \\
\hline $\begin{array}{l}\text { Sparing } \\
\text { et al., } \\
2009\end{array}$ & $\begin{array}{l}10 \text { RBD } \\
\text { with } \\
\text { neglect (+ } \\
\text { young } \\
\text { controls) }\end{array}$ & $\begin{array}{l}\text { Double- } \\
\text { blind, sham- } \\
\text { controlled, } \\
\text { crossover }\end{array}$ & $2.9 \pm 3.5$ months & $1 \mathrm{~mA}$ & $10 \mathrm{~min}$ & $\begin{array}{l}1 \text { anodal } 1 \\
\text { cathodal } 1 \\
\text { sham }\end{array}$ & Offline & Rest & Right PPC & $\begin{array}{l}\text { Computerised line } \\
\text { bisection, visual search } \\
\text { task }\end{array}$ \\
\hline $\begin{array}{l}\text { Sunwoo } \\
\text { et al., } \\
2013\end{array}$ & $\begin{array}{l}10 \text { RBD } \\
\text { with } \\
\text { neglect }\end{array}$ & $\begin{array}{l}\text { Double- } \\
\text { blind, sham- } \\
\text { controlled, } \\
\text { crossover }\end{array}$ & $\begin{array}{l}27.8 \pm 60.4 \\
\text { months }\end{array}$ & $1 \mathrm{~mA}$ & $20 \mathrm{~min}$ & 1 real 1 sham & Offline & Rest & P cortices & $\begin{array}{l}\text { Line bisection, star } \\
\text { cancellation }\end{array}$ \\
\hline $\begin{array}{l}\text { Brem et } \\
\text { al., } 2014\end{array}$ & $\begin{array}{l}1 \text { RBD with } \\
\text { neglect and } \\
\text { hemianopia }\end{array}$ & Single-case & 23 days & $1 \mathrm{~mA}$ & $20 \mathrm{~min}$ & $\begin{array}{l}1 \text { daily per } 5 \\
\text { days per } 4 \\
\text { weeks }\end{array}$ & Online & $\begin{array}{l}\text { Eye movement } \\
\text { protocol }\end{array}$ & Right PPC & $\begin{array}{l}\text { TAP, NET (German } \\
\text { equivalent of BIT), ADL }\end{array}$ \\
\hline $\begin{array}{l}\text { Smit et } \\
\text { al., } 2015\end{array}$ & $\begin{array}{l}5 \text { RBD with } \\
\text { neglect }\end{array}$ & $\begin{array}{l}\text { Double- } \\
\text { blind, sham- } \\
\text { controlled, } \\
\text { crossover }\end{array}$ & $\begin{array}{l}58 \pm 52.27 \\
\text { months }\end{array}$ & $2 \mathrm{~mA}$ & $20 \mathrm{~min}$ & $\begin{array}{l}1 \text { daily for } 5 \\
\text { days }\end{array}$ & Offline & Rest & Right PPC & BIT total score \\
\hline $\begin{array}{l}\text { Ladavas } \\
\text { et al., } \\
2015\end{array}$ & $\begin{array}{l}30 \text { RBD } \\
\text { with } \\
\text { neglect (10 } \\
\text { per group) }\end{array}$ & $\begin{array}{l}\text { Double- } \\
\text { blind, sham- } \\
\text { controlled, } \\
\text { between }\end{array}$ & 3.2 months & $2 \mathrm{~mA}$ & $20 \mathrm{~min}$ & $\begin{array}{l}1 \text { daily for } 10 \\
\text { days }\end{array}$ & Online & $10^{\circ}$ prisms & P cortices & BIT total score \\
\hline
\end{tabular}




\begin{tabular}{|c|c|c|c|c|c|c|c|c|c|c|}
\hline $\begin{array}{l}\text { Bang \& } \\
\text { Bong, } \\
2015\end{array}$ & $\begin{array}{l}12 \text { RBD } \\
\text { with } \\
\text { neglect (6 } \\
\text { per group) }\end{array}$ & $\begin{array}{l}\text { Double- } \\
\text { blind, sham- } \\
\text { controlled, } \\
\text { between }\end{array}$ & $\begin{array}{l}1.5 \pm 1.5 \\
\text { months }\end{array}$ & $1 \mathrm{~mA}$ & $20 \mathrm{~min}$ & $\begin{array}{l}1 \text { daily for } 15 \\
\text { days }\end{array}$ & Offline & $\begin{array}{l}\text { Feedback } \\
\text { training }\end{array}$ & Right PPC & $\begin{array}{l}\text { Line bisection, motor-free } \\
\text { visual perception test, } \mathrm{BI}\end{array}$ \\
\hline $\begin{array}{l}\text { Yi et al., } \\
2016\end{array}$ & $\begin{array}{l}30 \text { RBD } \\
\text { with } \\
\text { neglect (10 } \\
\text { per group) }\end{array}$ & $\begin{array}{l}\text { Double- } \\
\text { blind, sham- } \\
\text { controlled, } \\
\text { between }\end{array}$ & Subacute & $2 \mathrm{~mA}$ & $30 \mathrm{~min}$ & $\begin{array}{l}1 \text { daily per } 15 \\
\text { days }\end{array}$ & Online & $\begin{array}{l}\text { Conventional } \\
\text { OT }\end{array}$ & Right PPC & $\begin{array}{l}\text { Line bisection, star } \\
\text { cancellation, Bl, motor- } \\
\text { free visual perception } \\
\text { test, CBS }\end{array}$ \\
\hline $\begin{array}{l}\text { Turgut et } \\
\text { al., } 2016\end{array}$ & $\begin{array}{l}20 \text { RBD, } 12 \\
\text { LBD with } \\
\text { neglect (16 } \\
\text { per group) }\end{array}$ & $\begin{array}{l}\text { Double- } \\
\text { blind, sham- } \\
\text { controlled, } \\
\text { between }\end{array}$ & $22.5 \pm 16$ days & $1.5-2 \mathrm{~mA}$ & $20 \mathrm{~min}$ & $\begin{array}{l}1 \text { daily for } 8 \\
\text { days }\end{array}$ & Online & $\begin{array}{l}\text { Optokinetic } \\
\text { training }\end{array}$ & P cortices & $\begin{array}{l}\text { Line bisection, apple } \\
\text { cancellation, CDT, } \\
\text { spontaneous body } \\
\text { orientation, FIM, early } \\
\text { rehabilitation/BI }\end{array}$ \\
\hline $\begin{array}{l}\text { O Shea et } \\
\text { al., } 2017\end{array}$ & $\begin{array}{l}3 \text { RBD with } \\
\text { neglect } \quad(+ \\
\text { young } \\
\text { controls) }\end{array}$ & $\begin{array}{l}\text { Longitudinal } \\
\text { case-series }\end{array}$ & Chronic & $1 \mathrm{~mA}$ & $20 \mathrm{~min}$ & $\begin{array}{l}1 \text { real one } \\
\text { sham }\end{array}$ & Online & $10^{\circ}$ prisms & Left M1 & $\begin{array}{l}\text { BIT, neglect battery } \\
\text { (cancellation tasks and } \\
\text { eye movements), GABA } \\
\text { concentration } \\
\text { (spectroscopy) }\end{array}$ \\
\hline $\begin{array}{l}\text { Bornheim } \\
\text { et al., } \\
2018\end{array}$ & $\begin{array}{l}4 \text { RBD with } \\
\text { neglect }\end{array}$ & $\begin{array}{l}\text { Case } \\
\text { reports }\end{array}$ & Acute & $2 \mathrm{~mA}$ & $20 \mathrm{~min}$ & $\begin{array}{l}1 \text { daily for } 4 \\
\text { weeks ( } 2 \text { real } \\
\text { and } 2 \text { sham) }\end{array}$ & Offline & Rest & Right M1 & $\begin{array}{l}\text { Star cancellation, line } \\
\text { bisection, CBS }\end{array}$ \\
\hline $\begin{array}{l}\text { Chieffo et } \\
\text { al., } 2019 \\
\text { (abstract) }\end{array}$ & $\begin{array}{l}15 \text { RBD } \\
\text { with } \\
\text { neglect }\end{array}$ & $\begin{array}{l}\text { Sham- } \\
\text { controlled, } \\
\text { crossover }\end{array}$ & Subacute & $1 \mathrm{~mA}$ & $10 \mathrm{~min}$ & $\begin{array}{l}1 \text { anodal } 1 \\
\text { cathodal } 1 \\
\text { sham }\end{array}$ & Online & $10^{\circ}$ prisms & $\begin{array}{l}\text { Parietal } \\
\text { cortices }\end{array}$ & Pointing straight ahead \\
\hline
\end{tabular}




\section{References}

Alonzo, A., Brassil, J., Taylor, J. L., Martin, D., \& Loo, C. K. (2012). Daily transcranial direct current stimulation (tDCS) leads to greater increases in cortical excitability than second daily transcranial direct current stimulation. Brain Stimul, 5(3), 208-213. doi:10.1016/j.brs.2011.04.006

Andrade, S. M., Ferreira, J. J. A., Rufino, T. S., Medeiros, G., Brito, J. D., da Silva, M. A., \& Moreira, R. N. (2017). Effects of different montages of transcranial direct current stimulation on the risk of falls and lower limb function after stroke. Neurol Res, 39(12), 1037-1043. doi:10.1080/01616412.2017.1371473

Antal, A., Terney, D., Poreisz, C., \& Paulus, W. (2007). Towards unravelling task-related modulations of neuroplastic changes induced in the human motor cortex. European Journal of Neuroscience, 26(9), 2687-2691. doi:10.1111/j.1460-9568.2007.05896.x

Azouvi, P., Bartolomeo, P., Beis, J. M., Perennou, D., Pradat-Diehl, P., \& Rousseaux, M. (2006). A battery of tests for the quantitative assessment of unilateral neglect. Restor Neurol Neurosci, 24(4-6), 273-285.

Bang, D. H., \& Bong, S. Y. (2015). Effect of combination of transcranial direct current stimulation and feedback training on visuospatial neglect in patients with subacute stroke: a pilot randomized controlled trial. J Phys Ther Sci, 27(9), 2759-2761. doi:10.1589/jpts.27.2759

Benwell, C. S., Learmonth, G., Miniussi, C., Harvey, M., \& Thut, G. (2015). Non-linear effects of transcranial direct current stimulation as a function of individual baseline performance: Evidence from biparietal tDCS influence on lateralized attention bias. Cortex, 69, 152-165. doi:10.1016/j.cortex.2015.05.007

Berryhill, M. E., \& Jones, K. T. (2012). tDCS selectively improves working memory in older adults with more education. Neurosci Lett, 521(2), 148-151. doi:10.1016/j.neulet.2012.05.074

Bikson, M., Grossman, P., Thomas, C., Zannou, A. L., Jiang, J., Adnan, T., Mourdoukoutas, A. P., Kronberg, G., Truong, D., \& Boggio, P. (2016). Safety of transcranial direct current stimulation: evidence based update 2016. Brain stimulation, 9(5), 641-661.

Bikson, M., Rahman, A., \& Datta, A. (2012). Computational Models of Transcranial Direct Current Stimulation. Clinical EEG and Neuroscience, 43(3), 176-183. doi:10.1177/1550059412445138

Bolognini, N., Convento, S., Banco, E., Mattioli, F., Tesio, L., \& Vallar, G. (2014). Improving ideomotor limb apraxia by electrical stimulation of the left posterior parietal cortex. Brain, 138(2), 428-439. doi:10.1093/brain/awu343

Bornheim, S., Croisier, J.-L., Maquet, P., \& Kaux, J.-F. (2019). Transcranial Direct Current Stimulation ASsociated With Physical-therapy In Acute Stroke Patients - the tDCS ASAP - a Randomized, Triple Blind, Sham-controlled Study. Brain stimulation. doi:https://doi.org/10.1016/j.brs.2019.10.019

Bornheim, S., Maquet, P., Croisier, J. L., Crielaard, J. M., \& Kaux, J. F. (2018). Motor cortex Transcranial Direct Current Stimulation (tDCS) improves acute stroke visuo-spatial neglect: A series of four case reports. Brain Stimul, 11(2), 459-461. doi:10.1016/j.brs.2017.11.018

Bowen, A., McKenna, K., \& Tallis, R. C. (1999). Reasons for variability in the reported rate of occurrence of unilateral spatial neglect after stroke. Stroke, 30(6), 1196-1202. doi:10.1161/01.str.30.6.1196 
Bradnam, L., Stinear, C., \& Byblow, W. (2013). Ipsilateral Motor Pathways after Stroke: Implications for Non-Invasive Brain Stimulation. Frontiers in Human Neuroscience, 7(184). doi:10.3389/fnhum.2013.00184

Bradnam, L. V., Stinear, C. M., Barber, P. A., \& Byblow, W. D. (2012). Contralesional hemisphere control of the proximal paretic upper limb following stroke. Cereb Cortex, 22(11), 2662-2671. doi:10.1093/cercor/bhr344

Brem, A.-K., Unterburger, E., Speight, I., \& Jäncke, L. (2014). Treatment of visuospatial neglect with biparietal tDCS and cognitive training: a single-case study. Frontiers in systems neuroscience, 8, 180.

Brem, A. K., Unterburger, E., Speight, I., \& Jancke, L. (2014). Treatment of visuospatial neglect with biparietal tDCS and cognitive training: a single-case study. Front Syst Neurosci, 8, 180. doi:10.3389/fnsys.2014.00180

Brosnan, M. B., Arvaneh, M., Harty, S., Maguire, T., O'Connell, R., Robertson, I. H., \& Dockree, P. M. (2018). Prefrontal Modulation of Visual Processing and Sustained Attention in Aging, a tDCS-EEG Coregistration Approach. J Cogn Neurosci, 30(11), 1630-1645. doi:10.1162/jocn_a_01307

Brozzoli, C., Demattè, M. L., Pavani, F., Frassinetti, F., \& Farnè, A. (2006). Neglect and extinction: within and between sensory modalities. Restor Neurol Neurosci, 24(4-6), 217-232.

Brückner, S., \& Kammer, T. (2017). Both anodal and cathodal transcranial direct current stimulation improves semantic processing. Neuroscience, 343, 269-275. doi:https://doi.org/10.1016/j.neuroscience.2016.12.015

Buxbaum, L. J., Ferraro, M. K., Veramonti, T., Farne, A., Whyte, J., Ladavas, E., Frassinetti, F., \& Coslett, H. B. (2004). Hemispatial neglect: Subtypes, neuroanatomy, and disability. Neurology, 62(5), 749-756. doi:10.1212/01.wnl.0000113730.73031.f4

Cappon, D., Jahanshahi, M., \& Bisiacchi, P. (2016). Value and Efficacy of Transcranial Direct Current Stimulation in the Cognitive Rehabilitation: A Critical Review Since 2000. Frontiers in Neuroscience, 10(157). doi:10.3389/fnins.2016.00157

Cazzoli, D., Muri, R. M., Schumacher, R., von Arx, S., Chaves, S., Gutbrod, K., Bohlhalter, S., Bauer, D., Vanbellingen, T., Bertschi, M., Kipfer, S., Rosenthal, C. R., Kennard, C., Bassetti, C. L., \& Nyffeler, T. (2012). Theta burst stimulation reduces disability during the activities of daily living in spatial neglect. Brain, 135(Pt 11), 3426-3439. doi:10.1093/brain/aws182

Cherney, L. R., Halper, A. S., Kwasnica, C. M., Harvey, R. L., \& Zhang, M. (2001). Recovery of functional status after right hemisphere stroke: relationship with unilateral neglect. Archives of physical medicine and rehabilitation, 82(3), 322-328.

Chieffo, R., Arcari, C., Comi, G., Comola, M., \& Leocani, L. (2019). Effects of tDCS in modulating the after-effect of prismatic lenses training in stroke patients with neglect. Clinical neurophysiology, 130(1), e15. doi:https://doi.org/10.1016/j.clinph.2018.09.088

Corbetta, M., \& Shulman, G. L. (2011). Spatial neglect and attention networks. Annu Rev Neurosci, 34, 569-599. doi:10.1146/annurev-neuro-061010-113731

Dalmaijer, E. S., Li, K. M. S., Gorgoraptis, N., Leff, A. P., Cohen, D. L., Parton, A. D., Husain, M., \& Malhotra, P. A. (2018). Randomised, double-blind, placebo-controlled crossover study of single-dose guanfacine in unilateral neglect following stroke. $J$ Neurol Neurosurg Psychiatry, 89(6), 593-598. doi:10.1136/jnnp-2017-317338 
Datta, A., Bansal, V., Diaz, J., Patel, J., Reato, D., \& Bikson, M. (2009). Gyri-precise head model of transcranial direct current stimulation: improved spatial focality using a ring electrode versus conventional rectangular pad. Brain Stimul, 2(4), 201-207, 207.e201. doi:10.1016/j.brs.2009.03.005

Denes, G., Semenza, C., Stoppa, E., \& Lis, A. (1982). Unilateral spatial neglect and recovery from hemiplegia: a follow-up study. Brain, 105 (Pt 3), 543-552. doi:10.1093/brain/105.3.543

Di Lazzaro, V., Dileone, M., Capone, F., Pellegrino, G., Ranieri, F., Musumeci, G., Florio, L., Di Pino, G., \& Fregni, F. (2014). Immediate and late modulation of interhemipheric imbalance with bilateral transcranial direct current stimulation in acute stroke. Brain Stimul, 7(6), 841-848. doi:10.1016/j.brs.2014.10.001

Dmochowski, J. P., Datta, A., Bikson, M., Su, Y., \& Parra, L. C. (2011). Optimized multielectrode stimulation increases focality and intensity at target. J Neural Eng, 8(4), 046011. doi:10.1088/1741-2560/8/4/046011

Dmochowski, J. P., Datta, A., Huang, Y., Richardson, J. D., Bikson, M., Fridriksson, J., \& Parra, L. C. (2013). Targeted transcranial direct current stimulation for rehabilitation after stroke. Neuroimage, 75, 12-19. doi:10.1016/j.neuroimage.2013.02.049

Dmochowski, J. P., Koessler, L., Norcia, A. M., Bikson, M., \& Parra, L. C. (2017). Optimal use of EEG recordings to target active brain areas with transcranial electrical stimulation. Neuroimage, 157, 69-80. doi:10.1016/j.neuroimage.2017.05.059

Duncan, J., Bundesen, C., Olson, A., Humphreys, G., Chavda, S., \& Shibuya, H. (1999). Systematic analysis of deficits in visual attention. J Exp Psychol Gen, 128(4), 450-478.

Fernandez-Corazza, M., Turovets, S., Luu, P., Anderson, E., \& Tucker, D. (2016). Transcranial Electrical Neuromodulation Based on the Reciprocity Principle. Front Psychiatry, 7, 87. doi:10.3389/fpsyt.2016.00087

Filmer, H. L., Mattingley, J. B., \& Dux, P. E. (2019). Modulating brain activity and behaviour with tDCS: rumours of its death have been greatly exaggerated. Cortex. doi:https://doi.org/10.1016/j.cortex.2019.10.006

Fridriksson, J., Rorden, C., Elm, J., Sen, S., George, M. S., \& Bonilha, L. (2018). Transcranial Direct Current Stimulation vs Sham Stimulation to Treat Aphasia After Stroke: A Randomized Clinical Trial. JAMA Neurol, 75(12), 1470-1476. doi:10.1001/jamaneurol.2018.2287

Fruhmann Berger, M., Pross, R. D., Ilg, U., \& Karnath, H. O. (2006). Deviation of eyes and head in acute cerebral stroke. BMC Neurol, 6, 23. doi:10.1186/1471-2377-6-23

Fu, W., Song, W., Zhang, Y., Yang, Y., Huo, S., Zhang, R., \& Wang, M. (2015). Long-term effects of continuous theta-burst stimulation in visuospatial neglect. J Int Med Res, 43(2), 196-203. doi:10.1177/0300060513498663

Gandiga, P. C., Hummel, F. C., \& Cohen, L. G. (2006). Transcranial DC stimulation (tDCS): a tool for double-blind sham-controlled clinical studies in brain stimulation. Clinical neurophysiology, 117(4), 845-850.

Greinacher, R., Buhôt, L., Möller, L., \& Learmonth, G. (2019). The time course of ineffective sham-blinding during low-intensity $(1 \mathrm{~mA})$ transcranial direct current stimulation. European Journal of Neuroscience, 50(8), 3380-3388. doi:10.1111/ejn.14497

Guler, S., Dannhauer, M., Erem, B., Macleod, R., Tucker, D., Turovets, S., Luu, P., Erdogmus, D., \& Brooks, D. H. (2016). Optimization of focality and direction in dense electrode array transcranial direct current stimulation (tDCS). J Neural Eng, 13(3), 036020. doi:10.1088/1741-2560/13/3/036020 
Harvey, M., Hood, B., North, A., \& Robertson, I. H. (2003). The effects of visuomotor feedback training on the recovery of hemispatial neglect symptoms: assessment of a 2-week and follow-up intervention. Neuropsychologia, 41(8), 886-893. doi:10.1016/s0028-3932(03)00003-4

Harvey, M., \& Kerkhoff, G. (2015). Effects of non-invasive brain stimulation on attention: Current debates, cognitive studies and novel clinical applications. Neuropsychologia, 74, 1-6. doi:https://doi.org/10.1016/j.neuropsychologia.2015.06.020

Heilman, K. M., Valenstein, E., \& Watson, R. T. (2000). Neglect and related disorders. Semin Neurol, 20(4), 463-470. doi:10.1055/s-2000-13179

Hesse, M. D., Sparing, R., \& Fink, G. R. (2011). Ameliorating spatial neglect with non-invasive brain stimulation: from pathophysiological concepts to novel treatment strategies. Neuropsychol Rehabil, 21(5), 676-702. doi:10.1080/09602011.2011.573931

Hjaltason, H., Tegner, R., Tham, K., Levander, M., \& Ericson, K. (1996). Sustained attention and awareness of disability in chronic neglect. Neuropsychologia, 34(12), 1229-1233. doi:10.1016/0028-3932(96)00044-9

Holland, R., \& Crinion, J. (2012). Can tDCS enhance treatment of aphasia after stroke? Aphasiology, 26(9), 1169-1191. doi:10.1080/02687038.2011.616925

Horvath, J. C., Forte, J. D., \& Carter, O. (2015). Evidence that transcranial direct current stimulation (tDCS) generates little-to-no reliable neurophysiologic effect beyond MEP amplitude modulation in healthy human subjects: A systematic review. Neuropsychologia, 66, 213-236. doi:10.1016/j.neuropsychologia.2014.11.021

Husain, M. (2008). Hemispatial neglect. Handb Clin Neurol, 88, 359-372. doi:10.1016/S00729752(07)88018-3

Husain, M., \& Rorden, C. (2003). Non-spatially lateralized mechanisms in hemispatial neglect. Nat Rev Neurosci, 4(1), 26-36. doi:10.1038/nrn1005

Husain, M., Shapiro, K., Martin, J., \& Kennard, C. (1997). Abnormal temporal dynamics of visual attention in spatial neglect patients. Nature, 385(6612), 154-156. doi:10.1038/385154a0

Jacobson, L., Koslowsky, M., \& Lavidor, M. (2012). tDCS polarity effects in motor and cognitive domains: a meta-analytical review. Experimental brain research, 216(1), 110.

Jacquin-Courtois, S. (2015). Hemi-spatial neglect rehabilitation using non-invasive brain stimulation: or how to modulate the disconnection syndrome? Ann Phys Rehabil Med, 58(4), 251-258. doi:10.1016/j.rehab.2015.07.388

Jamil, A., Batsikadze, G., Kuo, H.-I., Labruna, L., Hasan, A., Paulus, W., \& Nitsche, M. A. (2017). Systematic evaluation of the impact of stimulation intensity on neuroplastic after-effects induced by transcranial direct current stimulation. The Journal of physiology, 595(4), 1273-1288. doi:10.1113/JP272738

Jehkonen, M., Ahonen, J. P., Dastidar, P., Koivisto, A. M., Laippala, P., Vilkki, J., \& Molnar, G. (2001). Predictors of discharge to home during the first year after right hemisphere stroke. Acta Neurol Scand, 104(3), 136-141. doi:10.1034/j.1600-0404.2001.00025.x

Jo, J. M., Kim, Y. H., Ko, M. H., Ohn, S. H., Joen, B., \& Lee, K. H. (2009). Enhancing the working memory of stroke patients using tDCS. Am J Phys Med Rehabil, 88(5), 404409. doi:10.1097/PHM.0b013e3181a0e4cb

Johansen-Berg, H., Rushworth, M. F. S., Bogdanovic, M. D., Kischka, U., Wimalaratna, S., \& Matthews, P. M. (2002). The role of ipsilateral premotor cortex in hand movement 
after stroke. Proceedings of the National Academy of Sciences, 99(22), 14518-14523. doi:10.1073/pnas.222536799

Kalra, L., Perez, I., Gupta, S., \& Wittink, M. (1997). The influence of visual neglect on stroke rehabilitation. Stroke, 28(7), 1386-1391.

Kang, E.-K., Kim, D.-Y., \& Paik, N.-J. (2012). Transcranial direct current stimulation of the left prefrontal cortex improves attention in patients with traumatic brain injury: a pilot study. Journal of rehabilitation medicine, 44(4), 346-350.

Kang, E. K., Baek, M. J., Kim, S., \& Paik, N. J. (2009). Non-invasive cortical stimulation improves post-stroke attention decline. Restor Neurol Neurosci, 27(6), 645-650. doi:10.3233/rnn-2009-0514

Karnath, H. O. (1988). Deficits of attention in acute and recovered visual hemi-neglect. Neuropsychologia, 26(1), 27-43. doi:10.1016/0028-3932(88)90028-0

Katz, N., Hartman-Maeir, A., Ring, H., \& Soroker, N. (1999). Functional disability and rehabilitation outcome in right hemisphere damaged patients with and without unilateral spatial neglect. Archives of physical medicine and rehabilitation, 80(4), 379-384.

Kekic, M., Boysen, E., Campbell, I. C., \& Schmidt, U. (2016). A systematic review of the clinical efficacy of transcranial direct current stimulation (tDCS) in psychiatric disorders. J Psychiatr Res, 74, 70-86. doi:10.1016/j.jpsychires.2015.12.018

Kessler, S. K., Turkeltaub, P. E., Benson, J. G., \& Hamilton, R. H. (2012). Differences in the experience of active and sham transcranial direct current stimulation. Brain stimulation, 5(2), 155-162.

Kim, Y. M., Chun, M. H., Yun, G. J., Song, Y. J., \& Young, H. E. (2011). The effect of virtual reality training on unilateral spatial neglect in stroke patients. Annals of rehabilitation medicine, 35(3), 309-315. doi:10.5535/arm.2011.35.3.309

Kinsbourne, M. (1987). Mechanisms of Unilateral Neglect. In M. Jeannerod (Ed.), Advances in Psychology (Vol. 45, pp. 69-86): North-Holland.

Kinsbourne, M. (1993). Orientational bias model of unilateral neglect: evidence from attentional gradients within hemispace. In J. Marshall \& I. Robertson (Eds.), Unilateral Neglect: Clinical And Experimental Studies (Brain Damage, Behaviour and Cognition) (pp. 63-86): Psychology Press.

Klaus, J., \& Schutter, D. J. L. G. (2018). Putting focus on transcranial direct current stimulation in language production studies. PloS one, 13(8), e0202730-e0202730. doi:10.1371/journal.pone.0202730

Knotkova, H., Nitsche, M. A., Bikson, M., \& Woods, A. J. (2019). Practical Guide to Transcranial Direct Current Stimulation: Principles, Procedures and Applications: Springer.

Ko, M. H., Han, S. H., Park, S. H., Seo, J. H., \& Kim, Y. H. (2008). Improvement of visual scanning after DC brain polarization of parietal cortex in stroke patients with spatial neglect. Neurosci Lett, 448(2), 171-174. doi:10.1016/j.neulet.2008.10.050

Koch, G., Bonnì, S., Giacobbe, V., Bucchi, G., Basile, B., Lupo, F., Versace, V., Bozzali, M., \& Caltagirone, C. (2012). Theta-burst stimulation of the left hemisphere accelerates recovery of hemispatial neglect. Neurology, 78(1), 24-30. doi:10.1212/WNL.0b013e31823ed08f

Kolb, B., Teskey, C., \& Gibb, R. (2010). Factors influencing cerebral plasticity in the normal and injured brain. Frontiers in Human Neuroscience, 4(204). doi:10.3389/fnhum.2010.00204 
Kuo, H. I., Bikson, M., Datta, A., Minhas, P., Paulus, W., Kuo, M. F., \& Nitsche, M. A. (2013). Comparing cortical plasticity induced by conventional and high-definition $4 \times 1$ ring tDCS: a neurophysiological study. Brain Stimul, 6(4), 644-648. doi:10.1016/j.brs.2012.09.010

Ladavas, E., Berti, A., Ruozzi, E., \& Barboni, F. (1997). Neglect as a deficit determined by an imbalance between multiple spatial representations. Exp Brain Res, 116(3), 493-500. doi:10.1007/pl00005777

Ladavas, E., Giulietti, S., Avenanti, A., Bertini, C., Lorenzini, E., Quinquinio, C., \& Serino, A. (2015). a-tDCS on the ipsilesional parietal cortex boosts the effects of prism adaptation treatment in neglect. Restor Neurol Neurosci, 33(5), 647-662. doi:10.3233/rnn-140464

Lang, N., Siebner, H. R., Ward, N. S., Lee, L., Nitsche, M. A., Paulus, W., Rothwell, J. C., Lemon, R. N., \& Frackowiak, R. S. (2005). How does transcranial DC stimulation of the primary motor cortex alter regional neuronal activity in the human brain? Eur $\mathrm{J}$ Neurosci, 22(2), 495-504. doi:10.1111/j.1460-9568.2005.04233.x

Learmonth, G., Benwell, C. S. Y., Märker, G., Dascalu, D., Checketts, M., Santosh, C., Barber, M., Walters, M., Muir, K. W., \& Harvey, M. (2020). Non-invasive brain stimulation in Stroke patients (NIBS): A prospective randomized open blinded end-point (PROBE) feasibility trial using transcranial direct current stimulation (tDCS) in post-stroke hemispatial neglect. Neuropsychological Rehabilitation, 1-27. doi:10.1080/09602011.2020.1767161

Learmonth, G., Thut, G., Benwell, C. S., \& Harvey, M. (2015). The implications of statedependent tDCS effects in aging: Behavioural response is determined by baseline performance. Neuropsychologia, 74, 108-119. doi:10.1016/j.neuropsychologia.2015.01.037

Li, K., Bentley, P., Nair, A., Halse, O., Barker, G., Russell, C., Soto, D., \& Malhotra, P. A. (2018). Reward sensitivity predicts dopaminergic response in spatial neglect. Cortex. doi:https://doi.org/10.1016/j.cortex.2018.09.002

Li, K., \& Malhotra, P. A. (2015). Spatial neglect. Practical neurology, 15(5), 333-339. doi:10.1136/practneurol-2015-001115

Li, L. M., Uehara, K., \& Hanakawa, T. (2015). The contribution of interindividual factors to variability of response in transcranial direct current stimulation studies. Frontiers in cellular neuroscience, 9, 181-181. doi:10.3389/fncel.2015.00181

Li, L. M., Violante, I. R., Leech, R., Ross, E., Hampshire, A., Opitz, A., Rothwell, J. C., Carmichael, D. W., \& Sharp, D. J. (2019). Brain state and polarity dependent modulation of brain networks by transcranial direct current stimulation. Human brain mapping, 40(3), 904-915. doi:10.1002/hbm.24420

Li, L. M., Violante, I. R., Zimmerman, K., Leech, R., Hampshire, A., Patel, M., Opitz, A., McArthur, D., Jolly, A., Carmichael, D. W., \& Sharp, D. J. (2019). Traumatic axonal injury influences the cognitive effect of non-invasive brain stimulation. Brain, 142(10), 3280-3293. doi:10.1093/brain/awz252

Lindenberg, R., Nachtigall, L., Meinzer, M., Sieg, M. M., \& Flöel, A. (2013). Differential Effects of Dual and Unihemispheric Motor Cortex Stimulation in Older Adults. The Journal of Neuroscience, 33(21), 9176-9183. doi:10.1523/jneurosci.0055-13.2013

List, J., Lesemann, A., Kübke, J. C., Külzow, N., Schreiber, S. J., \& Flöel, A. (2015). Impact of tDCS on cerebral autoregulation in aging and in patients with cerebrovascular diseases. Neurology, 84(6), 626-628. doi:10.1212/wnl.0000000000001230 
Lorenz, R., Simmons, L. E., Monti, R. P., Arthur, J. L., Limal, S., Laakso, I., Leech, R., \& Violante, I. R. (2019). Efficiently searching through large tACS parameter spaces using closed-loop Bayesian optimization. Brain Stimulation: Basic, Translational, and Clinical Research in Neuromodulation, 12(6), 1484-1489. doi:10.1016/j.brs.2019.07.003

Luauté, J., Michel, C., Rode, G., Pisella, L., Jacquin-Courtois, S., Costes, N., Cotton, F., le Bars, D., Boisson, D., Halligan, P., \& Rossetti, Y. (2006). Functional anatomy of the therapeutic effects of prism adaptation on left neglect. Neurology, 66(12), 18591867. doi:10.1212/01.wnl.0000219614.33171.01

Malhotra, P., Coulthard, E. J., \& Husain, M. (2009). Role of right posterior parietal cortex in maintaining attention to spatial locations over time. Brain, 132(Pt 3), 645-660. doi:10.1093/brain/awn350

Malhotra, P., Mannan, S., Driver, J., \& Husain, M. (2004). Impaired spatial working memory: one component of the visual neglect syndrome? Cortex, 40(4-5), 667-676. doi:10.1016/s0010-9452(08)70163-1

Malhotra, P. A., Parton, A. D., Greenwood, R., \& Husain, M. (2006). Noradrenergic modulation of space exploration in visual neglect. Ann Neurol, 59(1), 186-190. doi:10.1002/ana.20701

Manly, T. (2002). Cognitive rehabilitation for unilateral neglect: Review. Neuropsychological Rehabilitation, 12(4), 289-310. doi:10.1080/0960201044000101

Marquez, J., van Vliet, P., McElduff, P., Lagopoulos, J., \& Parsons, M. (2015). Transcranial direct current stimulation (tDCS): does it have merit in stroke rehabilitation? A systematic review. Int J Stroke, 10(3), 306-316. doi:10.1111/ijs.12169

Mesulam, M. M. (2000). Attentional networks, confusional states, and neglect syndromes. In Principles of behavioral and cognitive neurology, 2nd ed. (pp. 174-256). New York, NY, US: Oxford University Press.

Minarik, T., Berger, B., Althaus, L., Bader, V., Biebl, B., Brotzeller, F., Fusban, T., Hegemann, J., Jesteadt, L., Kalweit, L., Leitner, M., Linke, F., Nabielska, N., Reiter, T., Schmitt, D., Spraetz, A., \& Sauseng, P. (2016). The Importance of Sample Size for Reproducibility of tDCS Effects. Frontiers in Human Neuroscience, 10, 453-453. doi:10.3389/fnhum.2016.00453

Moliadze, V., Antal, A., \& Paulus, W. (2010). Electrode-distance dependent after-effects of transcranial direct and random noise stimulation with extracephalic reference electrodes. Clinical neurophysiology, 121(12), 2165-2171.

Monte-Silva, K., Kuo, M. F., Hessenthaler, S., Fresnoza, S., Liebetanz, D., Paulus, W., \& Nitsche, M. A. (2013). Induction of late LTP-like plasticity in the human motor cortex by repeated non-invasive brain stimulation. Brain Stimul, 6(3), 424-432. doi:10.1016/j.brs.2012.04.011

Monte-Silva, K., Kuo, M. F., Liebetanz, D., Paulus, W., \& Nitsche, M. A. (2010). Shaping the optimal repetition interval for cathodal transcranial direct current stimulation (tDCS). J Neurophysiol, 103(4), 1735-1740. doi:10.1152/jn.00924.2009

Moreno-Duarte, I., Gebodh, N., Schestatsky, P., Guleyupoglu, B., Reato, D., Bikson, M., \& Fregni, F. (2014). Transcranial Electrical Stimulation. In The Stimulated Brain (pp. 3559).

Muller-Dahlhaus, F., \& Ziemann, U. (2015). Metaplasticity in human cortex. Neuroscientist, 21(2), 185-202. doi:10.1177/1073858414526645 
Müri, R. M., Cazzoli, D., Nef, T., Mosimann, U. P., Hopfner, S., \& Nyffeler, T. (2013). Noninvasive brain stimulation in neglect rehabilitation: an update. Frontiers in Human Neuroscience, 7, 248-248. doi:10.3389/fnhum.2013.00248

Mylius, V., Ayache, S. S., Zouari, H. G., Aoun-Sebaiti, M., Farhat, W. H., \& Lefaucheur, J. P. (2012). Stroke rehabilitation using noninvasive cortical stimulation: hemispatial neglect. Expert Rev Neurother, 12(8), 983-991. doi:10.1586/ern.12.78

Nelson, J. T., McKinley, R. A., Golob, E. J., Warm, J. S., \& Parasuraman, R. (2014). Enhancing vigilance in operators with prefrontal cortex transcranial direct current stimulation (tDCS). Neuroimage, 85 Pt 3, 909-917. doi:10.1016/j.neuroimage.2012.11.061

Nitsche, M. A., Cohen, L. G., Wassermann, E. M., Priori, A., Lang, N., Antal, A., Paulus, W., Hummel, F., Boggio, P. S., Fregni, F., \& Pascual-Leone, A. (2008). Transcranial direct current stimulation: State of the art 2008. Brain Stimul, 1(3), 206-223. doi:10.1016/j.brs.2008.06.004

Nitsche, M. A., Doemkes, S., Karakose, T., Antal, A., Liebetanz, D., Lang, N., Tergau, F., \& Paulus, W. (2007). Shaping the effects of transcranial direct current stimulation of the human motor cortex. Journal of neurophysiology, 97(4), 3109-3117.

Nitsche, M. A., Liebetanz, D., Lang, N., Antal, A., Tergau, F., \& Paulus, W. (2003). Safety criteria for transcranial direct current stimulation (tDCS) in humans. Clin Neurophysiol, 114(11), 2220-2222; author reply 2222-2223. doi:10.1016/s13882457(03)00235-9

Nitsche, M. A., \& Paulus, W. (2000). Excitability changes induced in the human motor cortex by weak transcranial direct current stimulation. The Journal of physiology, 527(3), 633-639.

Noetscher, G. M., Yanamadala, J., Makarov, S. N., \& Pascual-Leone, A. (2014). Comparison of cephalic and extracephalic montages for transcranial direct current stimulation-a numerical study. IEEE Transactions on Biomedical Engineering, 61(9), 2488-2498. doi:10.1109/TBME.2014.2322774

Nurmi, L., Ruuskanen, E. I., Nurmi, M., Koivisto, A. M., Parkkila, A. K., Numminen, H., Dastidar, P., \& Jehkonen, M. (2018). Occurrence and Recovery of Different NeglectRelated Symptoms in Right Hemisphere Infarct Patients during a 1-Year Follow-Up. J Int Neuropsychol Soc, 24(6), 617-628. doi:10.1017/S1355617718000176

Nyffeler, T., Cazzoli, D., Hess, C. W., \& Muri, R. M. (2009). One session of repeated parietal theta burst stimulation trains induces long-lasting improvement of visual neglect. Stroke, 40(8), 2791-2796. doi:10.1161/strokeaha.109.552323

O'Connell, N. E., Cossar, J., Marston, L., Wand, B. M., Bunce, D., Moseley, G. L., \& De Souza, L. H. (2012). Rethinking clinical trials of transcranial direct current stimulation: participant and assessor blinding is inadequate at intensities of $2 \mathrm{~mA}$. PloS one, 7(10), e47514. doi:10.1371/journal.pone.0047514

O'Shea, J., Boudrias, M. H., Stagg, C. J., Bachtiar, V., Kischka, U., Blicher, J. U., \& JohansenBerg, H. (2014). Predicting behavioural response to TDCS in chronic motor stroke. Neuroimage, 85 Pt 3, 924-933. doi:10.1016/j.neuroimage.2013.05.096

O'Shea, J., Revol, P., Cousijn, H., Near, J., Petitet, P., Jacquin-Courtois, S., Johansen-Berg, H., Rode, G., \& Rossetti, Y. (2017). Induced sensorimotor cortex plasticity remediates chronic treatment-resistant visual neglect. Elife, 6, e26602.

Ogden, J. A. (1985). Contralesional neglect of constructed visual images in right and left brain-damaged patients. Neuropsychologia, 23(2), 273-277. doi:10.1016/00283932(85)90112-5 
Olgiati, E., Violante, I., Li, L., Faraj, A., Sinclair, T., Crow, J., Wise, R., \& Malhotra, P. (2019). Targeted brain stimulation to ameliorate vigilance in stroke: a combined tDCS-fMRI approach. Brain Stimulation: Basic, Translational, and Clinical Research in Neuromodulation, 12(2), 573. doi:10.1016/j.brs.2018.12.899

Opitz, A., Falchier, A., Linn, G. S., Milham, M. P., \& Schroeder, C. E. (2017). Limitations of ex vivo measurements for in vivo neuroscience. Proceedings of the National Academy of Sciences, 114(20), 5243-5246.

Paolucci, S., Antonucci, G., Grasso, M. G., \& Pizzamiglio, L. (2001). The role of unilateral spatial neglect in rehabilitation of right brain-damaged ischemic stroke patients: a matched comparison. Archives of physical medicine and rehabilitation, 82(6), 743749.

Park, S.-H., Koh, E.-J., Choi, H.-Y., \& Ko, M.-H. (2013). A Double-Blind, Sham-Controlled, Pilot Study to Assess the Effects of the Concomitant Use of Transcranial Direct Current Stimulation with the Computer Assisted Cognitive Rehabilitation to the Prefrontal Cortex on Cognitive Functions in Patients with Stroke. J Korean Neurosurg Soc, 54(6), 484-488. doi:10.3340/jkns.2013.54.6.484

Peers, P. V., Cusack, R., \& Duncan, J. (2006). Modulation of spatial bias in the dual task paradigm: evidence from patients with unilateral parietal lesions and controls. Neuropsychologia, 44(8), 1325-1335. doi:10.1016/j.neuropsychologia.2006.01.033

Pirulli, C., Fertonani, A., \& Miniussi, C. (2013). The role of timing in the induction of neuromodulation in perceptual learning by transcranial electric stimulation. Brain stimulation, 6(4), 683-689.

Pirulli, C., Fertonani, A., \& Miniussi, C. (2014). Is neural hyperpolarization by cathodal stimulation always detrimental at the behavioral level? Frontiers in behavioral neuroscience, 8, 226-226. doi:10.3389/fnbeh.2014.00226

Pisella, L., Berberovic, N., \& Mattingley, J. B. (2004). Impaired working memory for location but not for colour or shape in visual neglect: a comparison of parietal and nonparietal lesions. Cortex, 40(2), 379-390. doi:10.1016/s0010-9452(08)70132-1

Pizzamiglio, L., Guariglia, C., Antonucci, G., \& Zoccolotti, P. (2006). Development of a rehabilitative program for unilateral neglect. Restor Neurol Neurosci, 24(4-6), 337345.

Polania, R., Nitsche, M. A., \& Ruff, C. C. (2018). Studying and modifying brain function with non-invasive brain stimulation. Nat Neurosci, 21(2), 174-187. doi:10.1038/s41593017-0054-4

Posner, M. I. (1980). Orienting of attention. Quarterly Journal of Experimental Psychology, 32(1), 3-25.

Reis, J., Robertson, E., Krakauer, J. W., Rothwell, J., Marshall, L., Gerloff, C., Wassermann, E., Pascual-Leone, A., Hummel, F., Celnik, P. A., Classen, J., Floel, A., Ziemann, U., Paulus, W., Siebner, H. R., Born, J., \& Cohen, L. G. (2008). Consensus: "Can tDCS and TMS enhance motor learning and memory formation?". Brain stimulation, 1(4), 363-369. doi:10.1016/j.brs.2008.08.001

Reis, J., Schambra, H. M., Cohen, L. G., Buch, E. R., Fritsch, B., Zarahn, E., Celnik, P. A., \& Krakauer, J. W. (2009). Noninvasive cortical stimulation enhances motor skill acquisition over multiple days through an effect on consolidation. Proceedings of the National Academy of Sciences, 106(5), 1590-1595. doi:10.1073/pnas.0805413106 
Robertson, I. H. (1993). The relationship between lateralised and nonlateralised attentional deficits in unilateral neglect. In I. H. R. J. C. Marshall (Ed.), Unilateral neglect: Clinical and experimental studies (pp. 257-278). London: Psychology Press.

Robertson, I. H. (2001). Do we need the "lateral" in unilateral neglect? Spatially nonselective attention deficits in unilateral neglect and their implications for rehabilitation. Neuroimage, 14(1 Pt 2), S85-90. doi:10.1006/nimg.2001.0838

Robertson, I. H., Manly, T., Beschin, N., Daini, R., Haeske-Dewick, H., Homberg, V., Jehkonen, M., Pizzamiglio, G., Shiel, A., \& Weber, E. (1997). Auditory sustained attention is a marker of unilateral spatial neglect. Neuropsychologia, 35(12), 1527-1532. doi:10.1016/s0028-3932(97)00084-5

Robertson, I. H., Mattingley, J. B., Rorden, C., \& Driver, J. (1998). Phasic alerting of neglect patients overcomes their spatial deficit in visual awareness. Nature, 395(6698), 169172. doi:10.1038/25993

Robertson, I. H., Nico, D., \& Hood, B. M. (1997). Believing what you feel: Using proprioceptive feedback to reduce unilateral neglect. Neuropsychology, 11(1), 53.

Robertson, I. H., \& North, N. (1993). Active and passive activation of left limbs: Influence on visual and sensory neglect. Neuropsychologia, 31(3), 293-300. doi:https://doi.org/10.1016/0028-3932(93)90093-F

Robertson, I. H., North, N. T., \& Geggie, C. (1992). Spatiomotor cueing in unilateral left neglect: three case studies of its therapeutic effects. Journal of Neurology, Neurosurgery \&amp; Psychiatry, 55(9), 799-805. doi:10.1136/jnnp.55.9.799

Robertson, I. H., Tegner, R., Tham, K., Lo, A., \& Nimmo-Smith, I. (1995). Sustained attention training for unilateral neglect: theoretical and rehabilitation implications. $J$ Clin Exp Neuropsychol, 17(3), 416-430. doi:10.1080/01688639508405133

Rode, G., Lacour, S., Jacquin-Courtois, S., Pisella, L., Michel, C., Revol, P., Alahyane, N., Luaute, J., Gallagher, S., Halligan, P., Pelisson, D., \& Rossetti, Y. (2015). Long-term sensorimotor and therapeutical effects of a mild regime of prism adaptation in spatial neglect. A double-blind RCT essay. Ann Phys Rehabil Med, 58(2), 40-53. doi:10.1016/j.rehab.2014.10.004

Rossetti, Y., Rode, G., Pisella, L., Farne, A., Li, L., Boisson, D., \& Perenin, M. T. (1998). Prism adaptation to a rightward optical deviation rehabilitates left hemispatial neglect. Nature, 395(6698), 166-169. doi:10.1038/25988

Rossi, C., Sallustio, F., Di Legge, S., Stanzione, P., \& Koch, G. (2013). Transcranial direct current stimulation of the affected hemisphere does not accelerate recovery of acute stroke patients. Eur J Neurol, 20(1), 202-204. doi:10.1111/j.14681331.2012.03703.x

Rossit, S., Benwell, C. S. Y., Szymanek, L., Learmonth, G., McKernan-Ward, L., Corrigan, E., Muir, K., Reeves, I., Duncan, G., Birschel, P., Roberts, M., Livingstone, K., Jackson, H., Castle, P., \& Harvey, M. (2019). Efficacy of home-based visuomotor feedback training in stroke patients with chronic hemispatial neglect. Neuropsychological Rehabilitation, 29(2), 251-272. doi:10.1080/09602011.2016.1273119

Rosso, C., Valabregue, R., Arbizu, C., Ferrieux, S., Vargas, P., Humbert, F., Attal, Y., Messé, A., Zavanone, C., \& Meunier, S. (2014). Connectivity between right inferior frontal gyrus and supplementary motor area predicts after-effects of right frontal cathodal tDCS on picture naming speed. Brain stimulation, 7(1), 122-129. 
Ruf, S. P., Fallgatter, A. J., \& Plewnia, C. (2017). Augmentation of working memory training by transcranial direct current stimulation (tDCS). Scientific reports, 7(1), 876-876. doi:10.1038/s41598-017-01055-1

Ruffini, G., Fox, M. D., Ripolles, O., Miranda, P. C., \& Pascual-Leone, A. (2014). Optimization of multifocal transcranial current stimulation for weighted cortical pattern targeting from realistic modeling of electric fields. Neuroimage, 89, 216-225. doi:10.1016/j.neuroimage.2013.12.002

Russo, C., Carneiro, M., Bolognini, N., \& Fregni, F. (2017). Safety Review of Transcranial Direct Current Stimulation in Stroke. Neuromodulation : journal of the International Neuromodulation Society, 20. doi:10.1111/ner.12574

Sadleir, R. J., Vannorsdall, T. D., Schretlen, D. J., \& Gordon, B. (2012). Target optimization in transcranial direct current stimulation. Frontiers in psychiatry, 3, 90-90. doi:10.3389/fpsyt.2012.00090

Salazar, A. P. S., Vaz, P. G., Marchese, R. R., Stein, C., Pinto, C., \& Pagnussat, A. S. (2018). Noninvasive Brain Stimulation Improves Hemispatial Neglect After Stroke: A Systematic Review and Meta-Analysis. Archives of physical medicine and rehabilitation, 99(2), 355-366.e351. doi:https://doi.org/10.1016/j.apmr.2017.07.009

Sattler, V., Acket, B., Raposo, N., Albucher, J. F., Thalamas, C., Loubinoux, I., Chollet, F., \& Simonetta-Moreau, M. (2015). Anodal tDCS Combined With Radial Nerve Stimulation Promotes Hand Motor Recovery in the Acute Phase After Ischemic Stroke. Neurorehabil Neural Repair, 29(8), 743-754. doi:10.1177/1545968314565465

Saturnino, G. B., Madsen, K. H., Siebner, H. R., \& Thielscher, A. (2017). How to target interregional phase synchronization with dual-site Transcranial Alternating Current Stimulation. Neuroimage, 163, 68-80. doi:10.1016/j.neuroimage.2017.09.024

Schwippel, T., Papazova, I., Strube, W., Fallgatter, A. J., Hasan, A., \& Plewnia, C. (2018). Beneficial effects of anodal transcranial direct current stimulation (tDCS) on spatial working memory in patients with schizophrenia. Eur Neuropsychopharmacol, 28(12), 1339-1350. doi:10.1016/j.euroneuro.2018.09.009

Sedda, A., Borghese, N. A., Ronchetti, M., Mainetti, R., Pasotti, F., Beretta, G., \& Bottini, G. (2013). Using virtual reality to rehabilitate neglect. Behav Neurol, 26(3), 183-185. doi:10.3233/ben-2012-129006

Smit, M., Schutter, D. J., Nijboer, T. C., Visser-Meily, J. M., Kappelle, L. J., Kant, N., Penninx, J., \& Dijkerman, H. C. (2015). Transcranial direct current stimulation to the parietal cortex in hemispatial neglect: A feasibility study. Neuropsychologia, 74, 152-161. doi:10.1016/j.neuropsychologia.2015.04.014

Sparing, R., Thimm, M., Hesse, M., Küst, J., Karbe, H., \& Fink, G. (2009). Bidirectional alterations of interhemispheric parietal balance by non-invasive cortical stimulation. Brain, 132(11), 3011-3020.

Stagg, C. J., Bachtiar, V., O'Shea, J., Allman, C., Bosnell, R. A., Kischka, U., Matthews, P. M., \& Johansen-Berg, H. (2012). Cortical activation changes underlying stimulation-induced behavioural gains in chronic stroke. Brain, 135(Pt 1), 276-284. doi:10.1093/brain/awr313

Stagg, C. J., Jayaram, G., Pastor, D., Kincses, Z. T., Matthews, P. M., \& Johansen-Berg, H. (2011). Polarity and timing-dependent effects of transcranial direct current stimulation in explicit motor learning. Neuropsychologia, 49(5), 800-804. doi:10.1016/j.neuropsychologia.2011.02.009 
Stagg, C. J., \& Johansen-Berg, H. (2013). Studying the effects of transcranial direct-current stimulation in stroke recovery using magnetic resonance imaging. Front Hum Neurosci, 7, 857. doi:10.3389/fnhum.2013.00857

Stagg, C. J., \& Nitsche, M. A. (2011). Physiological basis of transcranial direct current stimulation. Neuroscientist, 17(1), 37-53. doi:10.1177/1073858410386614

Stone, S. P., Patel, P., \& Greenwood, R. J. (1993). Selection of acute stroke patients for treatment of visual neglect. Journal of neurology, neurosurgery, and psychiatry, 56(5), 463-466. doi:10.1136/jnnp.56.5.463

Stone, S. P., Patel, P., Greenwood, R. J., \& Halligan, P. W. (1992). Measuring visual neglect in acute stroke and predicting its recovery: the visual neglect recovery index. Journal of neurology, neurosurgery, and psychiatry, 55(6), 431-436. doi:10.1136/jnnp.55.6.431

Stone, S. P., Wilson, B., Wroot, A., Halligan, P. W., Lange, L. S., Marshall, J. C., \& Greenwood, R. J. (1991). The assessment of visuo-spatial neglect after acute stroke. Journal of neurology, neurosurgery, and psychiatry, 54(4), 345-350. doi:10.1136/jnnp.54.4.345

Striemer, C. L., Ferber, S., \& Danckert, J. (2013). Spatial working memory deficits represent a core challenge for rehabilitating neglect. Front Hum Neurosci, 7, 334. doi:10.3389/fnhum.2013.00334

Sunwoo, H., Kim, Y. H., Chang, W. H., Noh, S., Kim, E. J., \& Ko, M. H. (2013). Effects of dual transcranial direct current stimulation on post-stroke unilateral visuospatial neglect. Neurosci Lett, 554, 94-98. doi:10.1016/j.neulet.2013.08.064

Thimm, M., Fink, G. R., Kust, J., Karbe, H., \& Sturm, W. (2006). Impact of alertness training on spatial neglect: a behavioural and fMRI study. Neuropsychologia, 44(7), 12301246. doi:10.1016/j.neuropsychologia.2005.09.008

Tseng, P., Hsu, T. Y., Chang, C. F., Tzeng, O. J., Hung, D. L., Muggleton, N. G., Walsh, V., Liang, W. K., Cheng, S. K., \& Juan, C. H. (2012). Unleashing potential: transcranial direct current stimulation over the right posterior parietal cortex improves change detection in low-performing individuals. J Neurosci, 32(31), 10554-10561. doi:10.1523/jneurosci.0362-12.2012

Turgut, N., Miranda, M., Kastrup, A., Eling, P., \& Hildebrandt, H. (2016). tDCS combined with optokinetic drift reduces egocentric neglect in severely impaired post-acute patients Neuropsychol Rehabil, 28(4), 515-526. doi:10.1080/09602011.2016.1202120

Turi, Z., Csifcsák, G., Boayue, N. M., Aslaksen, P., Antal, A., Paulus, W., Groot, J., Hawkins, G. E., Forstmann, B., Opitz, A., Thielscher, A., \& Mittner, M. (2019). Blinding is compromised for transcranial direct current stimulation at $1 \mathrm{~mA}$ for $20 \mathrm{~min}$ in young healthy adults. European Journal of Neuroscience, 50(8), 3261-3268. doi:10.1111/ejn.14403

Vallar, G., \& Bolognini, N. (2011). Behavioural facilitation following brain stimulation: implications for neurorehabilitation. Neuropsychol Rehabil, 21(5), 618-649. doi:10.1080/09602011.2011.574050

Vallar, G., \& Bolognini, N. (2014). Unilateral Spatial Neglect. In A. C. Nobre \& S. Kastner (Eds.), Oxford Handbook of attention: Oxford University Press.

van Kessel, M. E., van Nes, I. J., Brouwer, W. H., Geurts, A. C., \& Fasotti, L. (2010). Visuospatial asymmetry and non-spatial attention in subacute stroke patients with and without neglect. Cortex, 46(5), 602-612. doi:10.1016/j.cortex.2009.06.004

Vernieri, F., Assenza, G., Maggio, P., Tibuzzi, F., Zappasodi, F., Altamura, C., Corbetto, M., Trotta, L., Palazzo, P., Ercolani, M., Tecchio, F., \& Rossini, P. M. (2010). Cortical 
neuromodulation modifies cerebral vasomotor reactivity. Stroke, 41(9), 2087-2090. doi:10.1161/strokeaha.110.583088

Wagner, S., Lucka, F., Vorwerk, J., Herrmann, C. S., Nolte, G., Burger, M., \& Wolters, C. H. (2016). Using reciprocity for relating the simulation of transcranial current stimulation to the EEG forward problem. Neuroimage, 140, 163-173.

Wagner, T., Fregni, F., Fecteau, S., Grodzinsky, A., Zahn, M., \& Pascual-Leone, A. (2007). Transcranial direct current stimulation: A computer-based human model study. Neuroimage, 35(3), 1113-1124. doi:https://doi.org/10.1016/j.neuroimage.2007.01.027

Wallace, D., Cooper, N. R., Paulmann, S., Fitzgerald, P. B., \& Russo, R. (2016). Perceived Comfort and Blinding Efficacy in Randomised Sham-Controlled Transcranial Direct Current Stimulation (tDCS) Trials at $2 \mathrm{~mA}$ in Young and Older Healthy Adults. PloS one, 11(2), e0149703-e0149703. doi:10.1371/journal.pone.0149703

Waters-Metenier, S., Husain, M., Wiestler, T., \& Diedrichsen, J. (2014). Bihemispheric transcranial direct current stimulation enhances effector-independent representations of motor synergy and sequence learning. J Neurosci, 34(3), 10371050. doi:10.1523/jneurosci.2282-13.2014

Wiethoff, S., Hamada, M., \& Rothwell, J. C. (2014). Variability in response to transcranial direct current stimulation of the motor cortex. Brain Stimul, 7(3), 468-475. doi:10.1016/j.brs.2014.02.003

Wilson, B., Cockburn, J., \& Halligan, P. (1987). Development of a behavioral test of visuospatial neglect. Arch Phys Med Rehabil, 68(2), 98-102.

Woods, A. J., Antal, A., Bikson, M., Boggio, P. S., Brunoni, A. R., Celnik, P., Cohen, L. G., Fregni, F., Herrmann, C. S., Kappenman, E. S., Knotkova, H., Liebetanz, D., Miniussi, C., Miranda, P. C., Paulus, W., Priori, A., Reato, D., Stagg, C., Wenderoth, N., \& Nitsche, M. A. (2016). A technical guide to tDCS, and related non-invasive brain stimulation tools. Clin Neurophysiol, 127(2), 1031-1048. doi:10.1016/j.clinph.2015.11.012

Yi, Y. G., Chun, M. H., Do, K. H., Sung, E. J., Kwon, Y. G., \& Kim, D. Y. (2016). The Effect of Transcranial Direct Current Stimulation on Neglect Syndrome in Stroke Patients. Ann Rehabil Med, 40(2), 223-229. doi:10.5535/arm.2016.40.2.223

Zaghi, S., Acar, M., Hultgren, B., Boggio, P. S., \& Fregni, F. (2010). Noninvasive brain stimulation with low-intensity electrical currents: putative mechanisms of action for direct and alternating current stimulation. Neuroscientist, 16(3), 285-307. doi:10.1177/1073858409336227

Zebhauser, P. T., Vernet, M., Unterburger, E., \& Brem, A.-K. (2019). Visuospatial Neglect - a Theory-Informed Overview of Current and Emerging Strategies and a Systematic Review on the Therapeutic Use of Non-invasive Brain Stimulation. Neuropsychology Review. doi:10.1007/s11065-019-09417-4

Zimmermann, P., \& Fimm, B. (2002). A test battery for attentional performance. In M. Leclercq \& P. Zimmermann (Eds.), Applied Neuropsychology of Attention. London: Psychology Press. 